\title{
An In Silico Analysis of Potential SARS-CoV-2 Interactions with Proteins Involved in Placental Functions
}

Ashikh A Seethy ${ }^{1 \#}$, Sunil Singh ${ }^{1 \#}$, Indrani Mukherjee ${ }^{1,2}$, Karthikeyan Pethusamy ${ }^{1}$, Kakali Purkayastha ${ }^{3}$, Jai Bhagwan Sharma ${ }^{4}$, Ruby Dhar ${ }^{1^{*}}$ and Subhradip Karmakar ${ }^{1^{*}}$

1= Department of Biochemistry, All India Institute of Medical Sciences, New Delhi, India

2= Amity Institute of Biotechnology, Noida, India

3= Department of Paediatrics, All India Institute of Medical Sciences, New Delhi, India

4= Department of Obstetrics and Gynaecology, All India Institute of Medical Sciences, New Delhi, India

\#: These authors contributed equally

*: Corresponding authors (rubydhar@gmail.com; subhradip.k@aiims.edu)

\section{Abstract:}

COVID-19 is a rapidly evolving medical emergency that has drawn global attention, unprecedented in any disease of its kind in recent times. The magnitude of the health crisis emerging from this pandemic has overwhelmed health care workers worldwide and called in for extraordinary measures to contain this virus. A simple Pubmed query on "COVID-19"

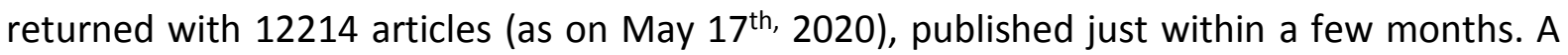
detailed survey revealed around 250 clinical reports, 8 clinical trials, 9 meta-analyses, and 906 reviews that were published during this time span. Combining the strings "COVID-19 and Pregnancy" yielded a total of 132 reports while querying "COVID-19 and Placenta" returned with just 11 articles Even taking into considerations that few materials are in the PrePrint Server, we still have a gross under-representation of studies addressing the effect of this disease on pregnancy outcome and maternal \& child health. An essential aspect of a successful pregnancy is proper placentation, where transiently invasive placental trophoblast cells invade the maternal endometrium to establish a functional feto-maternal communication. Based on the elegant study by David. E. Gordon, et al. published in Nature (April 30, 2020), which identified 332 human host proteins interacting with SARS-nCoV2 using an affinity-based purification, we interrogated several gene expression data sets available at $\mathrm{NCBI}-\mathrm{GEO}$ related to trophoblast invasion and differentiation. Both of these processes are indispensable for placentation and fetal survival. Our analysis showed several overlaps with the interactome proteins implying that SARS-CoV-2 infection can affect several proteins, which are crucial for trophoblasts function. GeneMANIA and STRING based functional analysis further revealed that several of that SARS-CoV-2 interacting trophoblast proteins as a hub for the protein-protein interaction network. Our study thus elucidates the possible effect of SARS-CoV-2 infection on placenta formation and pregnancy outcome.

Keywords: SARS-CoV-2, COVID-19, Pregnancy, Trophoblasts, Interactome, Placenta. 


\section{Background:}

COVID-19, the viral respiratory disease caused by Severe Acute Respiratory Syndrome Corona Virus 2 (SARS-CoV-2) was first reported in Wuhan, Hubei province, China, in December 2019. $(1,2)$ As on May 17, 2020, there had been 4,760,420 cases and 314,138 deaths attributed to COVID-19, the over-all mortality being 6.59\%.(3) Even though individuals with co-morbidities like hypertension, diabetes, cardiovascular disease, chronic respiratory disease and cancer, and individuals aged more than 60 years are at a higher risk for severe disease and death,(4) a large number of the affected individuals, indeed more than 50\% of COVID-19 patients, belong to the reproductive age group; (5) Close to $40 \%$ of the affected individuals are females.(6) Piecing all these information together, a large number of females in the reproductive age group have been already infected with SARS-Cov2, or are at potential risk of infection, given the R0 of about 2.28 of COVID-19.(7)

A characterization of pregnant females who were hospitalized for delivery during the COVID19 outbreak showed that $15.4 \%$ of these women were positive for SARS-CoV-2, and among . these, $87.9 \%$ were asymptomatic. Though the studies are limited, there is no evidence to suggest that the previous severe corona viral epidemics - Severe Acute Respiratory Syndrome (SARS) and Middle East Respiratory Syndrome (MERS) - were associated with increased disease susceptibility in pregnant females.(8) Though the currently limited data does not suggest increased COVID-19 severity in pregnant women compared to the general population, (9) since the physiological and mechanical adaptations in pregnancy are associated with increased susceptibility to infections especially those involving the cardiorespiratory system,(10) the absence of evidence at the early stage of this disease does not preclude this possibility of risk to both mother and the child.

The major consensus at this stage of COVID-19 is that there is no vertical transmission of SARSCoV-2, like the predecessor coronaviruses causing SARS and MERS, $(8,11-13)$ though there was one recent report on a probable case of vertical transmission.(14) SARS-CoV-2 infection in the third trimester of pregnancy was found to be associated with an increased risk of preterm delivery and intrauterine fetal distress and the requirement for Caesarean sections.(15) At present, there is limited data on the effect of SARS-CoV-2 infection during the first trimester of pregnancy on the pregnancy outcome. However, during SARS of 2003, pregnant females who presented with the disease during the first trimester had an adverse outcome, with $57 \%$ of pregnancies ending in spontaneous miscarriage, and 4 out of 5 patients who presented with the disease progressing into preterm delivery. (16) The reasons behind this adverse outcome in pregnancy in females infected with SARS-CoV remains enigmatic.

The placenta is a transient organ that mediates not only the mechanical function of attachment of the developing fetus to the uterus but also plays an indispensable role in facilitating gaseous exchange, transport of nutrients as well as the removal of waste product throughout the pregnancy.(17) Trophoblast cells derived from the outer trophectoderm layer of the developing blastocyst are the major cell types responsible for the formation of the placenta and the extraembryonic membranes, besides providing endocrine support, these cells have stem cell like properties capable of differentiating along several lineages each with a specialized function. Trophoblast cells differentiate into two layers - the mononuclear 
cytotrophoblasts (CTB) and multinucleated syncytiotrophoblasts (STB) (Figure 1). The former cells form the core of the primary, secondary and tertiary villi, while the syncytiotrophoblasts form the covering. The cytotrophoblasts function as undifferentiated progenitors for the overlaying syncytiotrophoblasts. The cytotrophoblast cells penetrate the syncytial layer to get in direct contact with the endometrium, where it attaches to the decidua via anchoring villi as part of trophoblast cell columns aided by the release of anchoring protein trophouteronectin.(18)

In addition to the exchange of gas and nutrients, the placenta is also a site for the bidirectional transfer of metabolites, small molecules as well as pathogens and viruses.(19) Though trophoblast cells of the placenta assist in the protective role against pathogens that may cross the maternal-fetal barrier, vertical transmission of pathogens like toxoplasma and listeria as well as viruses (Zika virus, rubella, cytomegalovirus, etc.) do take place in varied proportions. Most of these infections pose severe fetal complications and congenital abnormalities, leading to miscarriage as well as fetal death. In our present study, we plan to explore the harmful effects of SARS-CoV-2 on the placenta and the trophoblast cells in pregnant females with COVID-19 disease.

Since the placenta executes and orchestrates fetal growth-related pathways, placental dysfunction has deleterious effects on the outcome of pregnancy. The first step in addressing the question of whether an adverse pregnancy outcome can occur in SARS-CoV-2 infection is to study the interaction between SARS-CoV-2 and the proteins that are associated with important placental functions like invasion and differentiation. In this study, we use an insilico based approach, employing the SARS-CoV-2 human interactome, differential expression analysis of genes associated with critical placental functions to address the possible consequences of COVID-19 on pregnancy outcome.

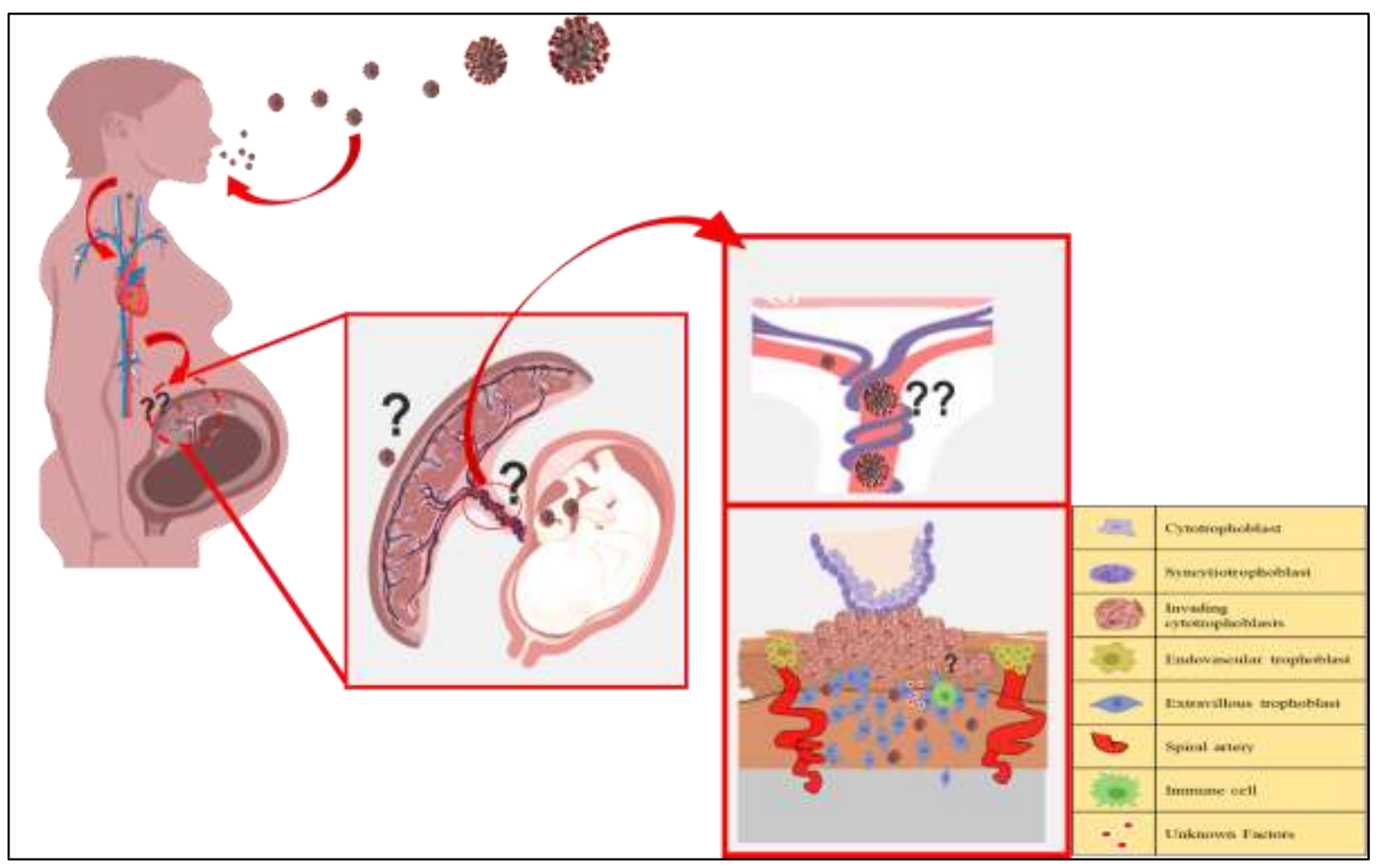


Figure 1: This study aims to decipher the potential interactions between the proteins of SARSCoV-2 and various proteins that are important in the key functions of placenta.

\section{Materials and Methods:}

\section{SARS-CoV-2 Human Interactome:}

Gordon et al. identified 332 proteins that can interact with 26 of the 29 SARS-CoV-2 proteins, using an affinity-purification (following cloning of viral proteins and their expression in HEK293T cells) and mass spectrometry approach.(20-22) These proteins are listed online (and in Supplementary Table 1)

\section{Identification of Proteins Involved in Crucial Functions of Placenta:}

Datasets from NCBI-GEO involving studies on placenta were analyzed for differential gene expression using GEO-2R. Briefly, GEO-2R uses two R-packages from the Bioconductor project - GEOquery, which parses the data to submit it to limma $\mathrm{R}$ - to make comparisons between the input samples. Limma stands for 'linear models for microarray analysis'; it is a statistical tool for identification of the differentially expressed genes in the input samples. The datasets used and the samples for differential expression are summarised in Table 1. The datasets were chosen to identify genes that are upregulated during various physiological processes and states involving the placenta - including invasion of trophoblasts, trophoblast differentiation, and disease conditions associated with pregnancy.

Table 1: Summary of Datasets Used to Study Placental Functions and Pathology

\begin{tabular}{|l|l|l|}
\hline Dataset & Condition & Figure No. \\
\hline GSE9984 & Term placenta vs First trimester placenta & Figure 3 \\
\hline GSE28551 & Term placenta vs First trimester placenta & Figure 3 \\
\hline GSE9773 & Villous vs Extravillous trophoblasts & Figure 6 \\
\hline GSE130339 & Day 7 (differentiated) vs day 0 (undifferentiated) trophoblasts & Figure 9 \\
\hline GSE20510 & JEG3 vs HTR-8/SVneo cell lines & Figure 15 \\
\hline GSE20510 & JEG3 vs SGHPL5 cell lines & Figure 15 \\
\hline GSE66273 & Pre-eclampsia vs Control placenta & Figure 19 \\
\hline GSE48424 & Pre-eclampsia vs Control placenta & Figure 19 \\
\hline
\end{tabular}

The significant differentially expressed genes were identified by a cut-off adjusted $p$-value of 0.05. The adjusted $p$-values were employed to minimize the false discovery rate. In this study, Benjamini \& Hochberg false discovery rate method was used to calculate the adjusted $p$ values. From the significant differentially expressed genes, those with a $\log _{2}$ fold change of $\geq$ 1 and $\leq-1$ were considered significant upregulated and downregulated, respectively.

Genes/proteins involved in critical placental functions or that are differentially expressed in placental pathology were also obtained by text mining, and literature search of studies involving such analysis - the genes that are upregulated in cytotrophoblasts, syncytiotrophoblasts and migratory trophoblasts were obtained from a study by West et al., (23) and the differentially expressed genes in gestational diabetes mellitus from a study by Radaelli et al.(24) 


\section{Identification of Proteins Involved in Placental Functions that can Bind to SARS-CoV-2:}

For each dataset, the significant upregulated and downregulated proteins that were identified as compared to the list of proteins interacting with SARS-CoV-2. The lists were compared using Venny 2.1.0 (25) to identify the overlapping proteins. The functions of the proteins that were recurring across multiple study scenarios were further analyzed using text mining and network analysis using GeneMANIA(26) and/or STRING(27) to evaluate their interactome and possible biological function.

A flow chart summarising the complete approach in the discovery of the proteins involved in placental functions that can bind to SARS-CoV-2 is given in Figure 2.

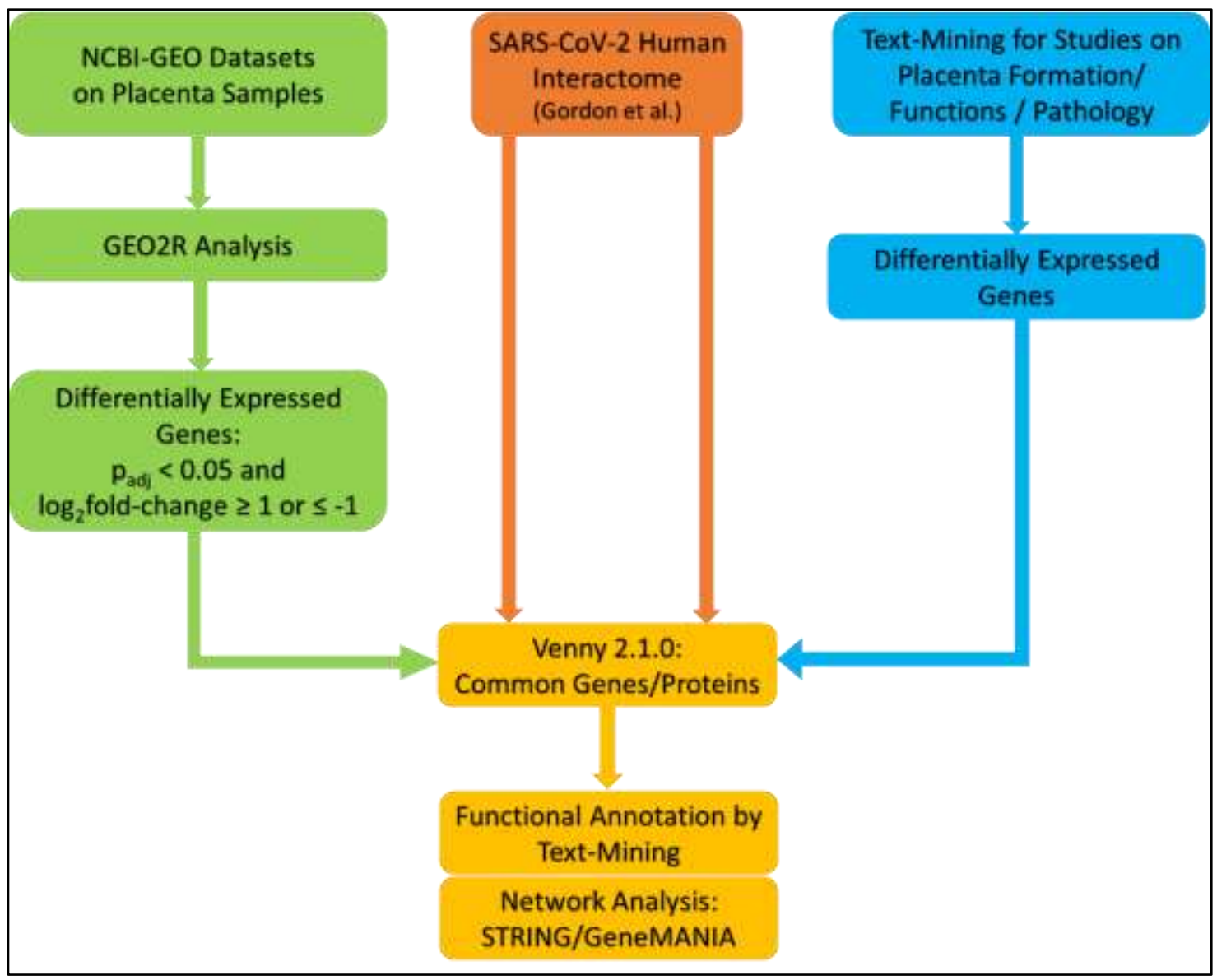

Figure 2: Summary of Workflow

\section{Identification of Common Elements in SARS-CoV-2 Human Interactome and Zika Virus Human Interactome:}

Since Zika virus infection in pregnancy has been proven to be associated with vertical transmission of the virus, and disruption of the placental physiology with alterations like abnormal blood flow and aberrant synthesis of biological mediators,(28) we also studied the possible overlap between the human proteins that interact with Zika virus and the SARS-CoV2 human interactome. For this, a list of human proteins from SK-N-BE2 neuroblastoma cells that interact with Zika viral proteins were obtained from a study by Scaturro et al.(29) These were compared with SARS-CoV-2 human interactome. The lists were compared using Venny 
2.1.0 and the relevance of the overlapping proteins in placental functions were studied using text-mining and network analysis.

\section{Results:}

\section{SARS-CoV-2 Interacting Proteins that are Upregulated in First Trimester and Term Placentas}

Analysis of two different datasets, GSE9984 and GSE28551, were performed to identify the SARS-CoV-2 interacting proteins that are upregulated in first-trimester placenta and term placenta. The data sets revealed that 3 proteins (GSE9984) and 14 proteins (GSE28551), upregulated in first-trimester placenta interacting with SARS-CoV-2 in the two queried data sets (Figures 3a and 3b). We further observed 21 proteins (GSE9984) and 19 proteins (GSE28551) that were upregulated in term placenta in these two data sets (Figures 3a and 3b) that could interact with SARS-CoV-2. We then identified the candidate proteins in the first trimester ( 3 and 14) and term placenta (21 and 19) that were common in the two data sets. Our results yielded LOX as a common candidate in the term placenta and SCARB1 and PRKAR2B in the first trimester that could potentially interact with CoV2 (Figure 3c).

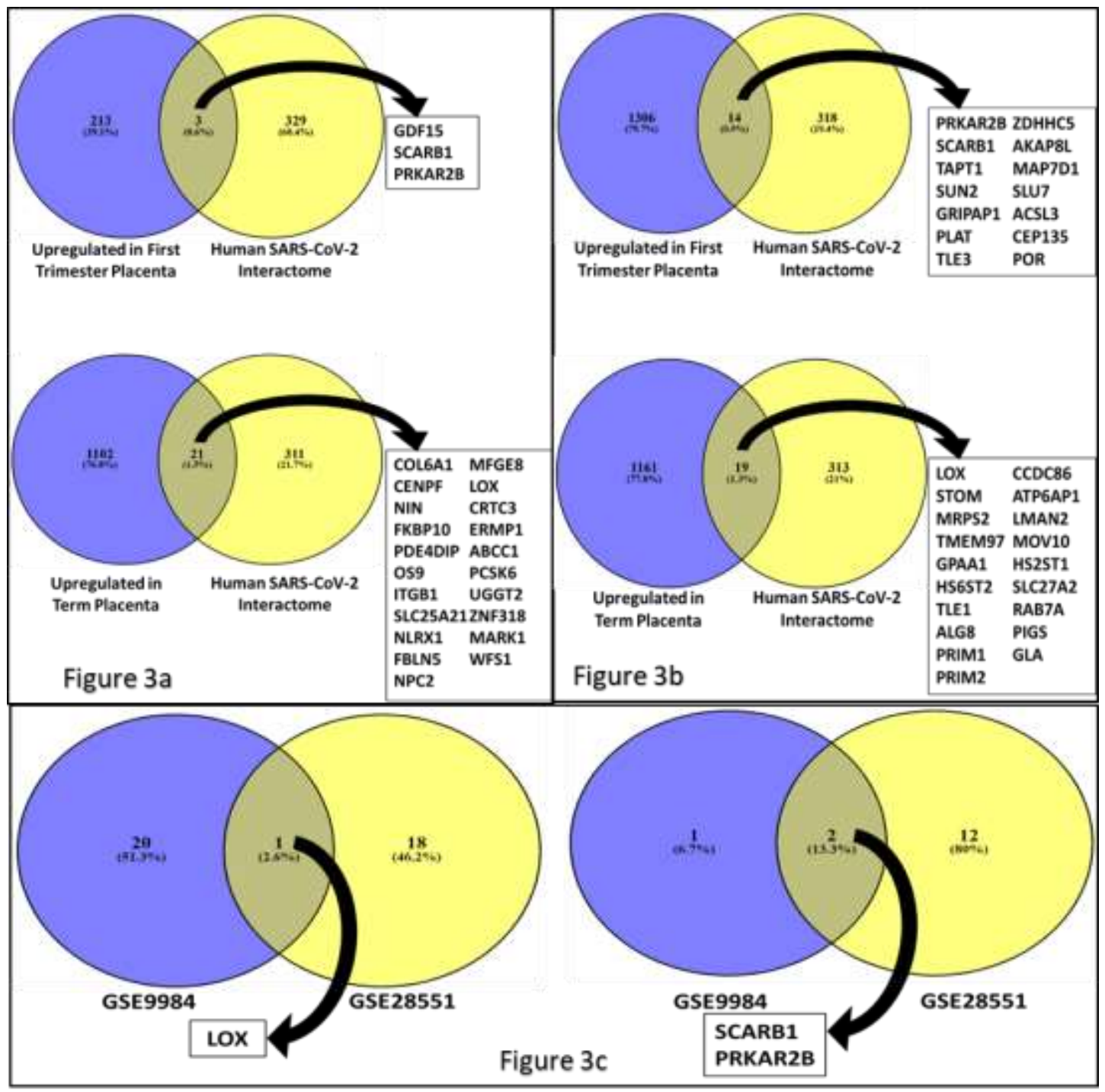

Figure 3: SARS-CoV-2 Interacting Proteins that are Upregulated in First Trimester Placenta and Term Placenta. Figures $3 a$ and $3 b$ show data from GSE9984 and GSE28551, respectively. 
Figure $3 c$ shows the overlapping proteins in term placenta (left) and first trimester placenta (right) from GSE9984 and GSE28551, that interact with SARS-CoV-2. The expansions of all the protein names and the SARS-COV-2 proteins interacting with them are given in Supplementary Table 2.

LOX (lysyl oxidase) upregulated in term placenta can interact with SARS-CoV-2 orf8. Since the downregulation of LOX has been implicated in impaired trophoblast migration and invasion (30), it will be interesting to further validate its interaction with SARS-CoV2 orf8 in an experimental system and study the outcome of this interaction in relation to trophoblast functions. The interaction network of LOX is shown in Figure 4.

SCARB1 and PRKAR2B were the two common first trimester proteins from both the datasets. Scavenger receptor class B type 1 or SCARB1 functions as the receptor for HDL and is important in HDL uptake by trophoblasts (31), and along with CD81, it forms the entry receptor for hepatitis $C,(32)$ which is an RNA virus-like SARS-CoV2. It interacts with SARS-CoV2 nsp7. PRKAR2B or CAMP-dependent protein kinase type II-beta regulatory subunit interacts with SARS-CoV2 nsp13.

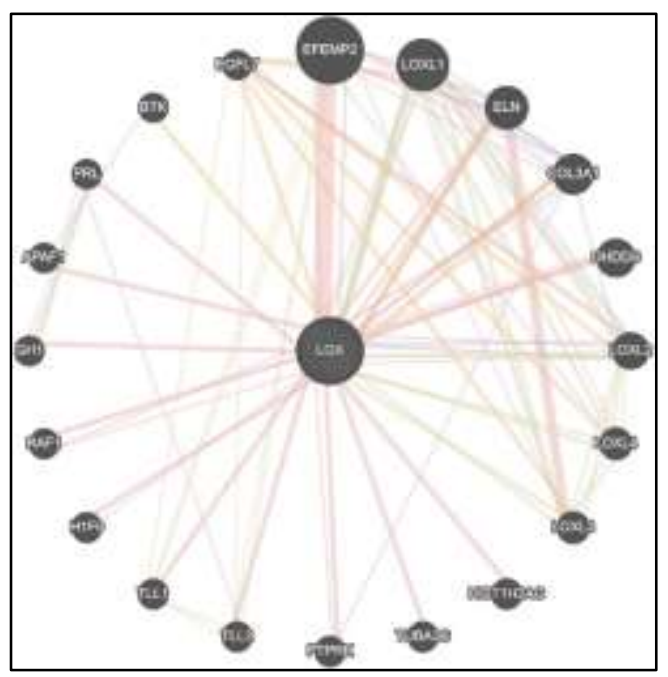

Figure 4: LOX interaction network

\section{SARS-CoV-2 Interacting Proteins that are Upregulated in Villous and Extravillous Trophoblasts}

Differentiation of trophoblast stem cells along villous and extravillous lineages is a critical early decision in the formation of the placenta and establishing effective feto-maternal communication (Figure 5). Mononuclear cytotrophoblasts (CTBs) forming placental villi through branching morphogenesis, give rise to mature tertiary villi forming villous cytotrophoblast (VCTB). Villous syncytiotrophoblast (VSTB) formed upon the fusion of this VCTB, forms the outer layers of the floating villi bathing in maternal blood that is drained into the intervillous space towards the chorionic plate coming from the basal plate. The VSTB also produces pregnancy steroid hormones and participates in exchange for oxygen and transport of nutrients,(33) a feat critical for supporting pregnancy. At sites where the villi interact with the decidua, forming trophoblast cell columns, a migratory lineage of trophoblast, called extravillous trophoblast (EVT) arises.(34) EVT can be found in various anatomical locations: in 
the chorionic plate, smooth chorion, the cell islands and columns, the basal plate, the placental septa, and in walls and lumina of uteroplacental vessels.(35) EVT is a complex heterogeneous population in itself, manifesting proliferative or invasive or both the characteristics.(35) Broadly, EVT can leave the placenta core and invade the maternal endometrium, interdigitating through the extracellular spaces of the endometrium and the myometrium. Few subpopulations of EVT arises, within the maternal uterine compartment interstitial CTBs (iCTBs), colonizing the decidual stroma, and endovascular CTBs (evCTBs), eroding and remodeling the maternal spiral arteries securing an uninterrupted blood flow towards the placenta. CTB lineage commitments and genesis of trophoblast subpopulations are indispensable for pregnancy, as evidenced in gestational trophoblastic orders arising due to defective trophoblast induced alterations at the feto-maternal interface. $(36,37)$

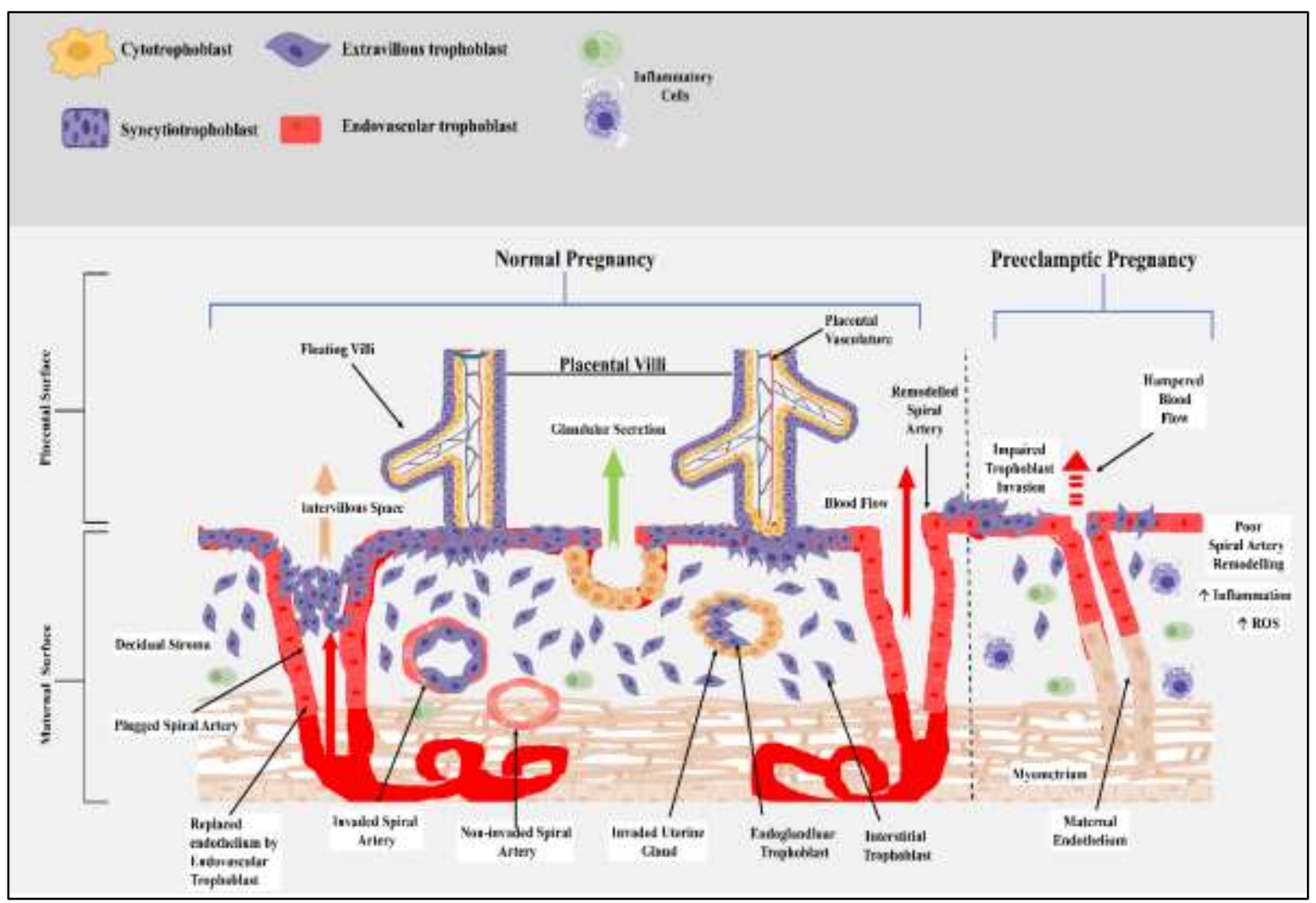

Figure 5: Trophoblast cells in Placenta interacting with maternal endometrium in Normal Pregnancy and in Preeclampsia

Considering the importance of both villous and extravillous lineages of trophoblast in placentation and fetal development(38) we investigated if SARS-CoV-2 interacting proteins are crucial during this differentiation program. We analyzed the villous and extravillous data set (GSE9773) (Figure 6). As mentioned above, the EVT populations are highly motile and exhibit a migratory phenotype, which enables them to leave the villous core and enter the maternal endometrium. As seen in the intersecting Venn, GSE9773 identified 5 common entries between villous CTB and SARS-CoV- 2 interactome. COL6A1 (collagen type VI $\alpha 1$ chain), identified as one target, is reported to play a critical role in cell migration (39) and cancer metastasis.(40) 


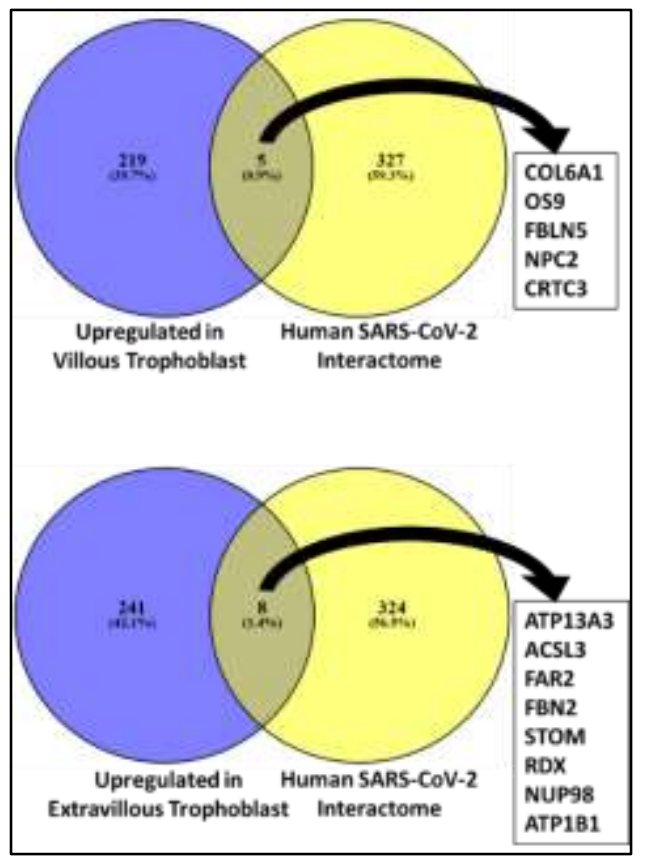

Figure 6: SARS-CoV-2 Interacting Proteins that are Upregulated in Villous and Extravillous Trophoblasts. The data was obtained by analysing GSE9984. The expansions of all the gene names are given in Supplementary Table 2.

Another target, FBLN5 (fibulin-5) is a member of the fibulin family that alters cell adhesive and invasive properties and is expressed in human villous cytotrophoblasts as reported by Winship, et al.(41) Derived from decidua and EVT; it regulates EVT invasion and placentation in women. Gauster, et al.(42) based on cell culture experiments with the villous trophoblastderived placental fusogenic cell line BeWo, showed that fibulin-5 expression was downregulated during functional differentiation and intercellular fusion. BeWo under hypoxia showed a reduced tendency to fuse, along with an increase in FBLN5 expression. Moore, et al.(43) localized major microfibrillar networks in amnion. Other targets NPC2 (along with NPC1) are required for egress of lysosomal cholesterol, by which cholesterol is removed from the late endocytic pathway.(44) Placenta has been an active steroidogenic tissue; this pathway is therefore of paramount importance, which can be perturbed upon interaction with SARS-CoV-2. We then identified the overlapping proteins between EVT and SARS-CoV-2 interactome, which yielded eight interacting members (GSE9984). FAR2 is abundantly expressed in placenta and trophoblast (Figure 7), but currently, its function is unknown.

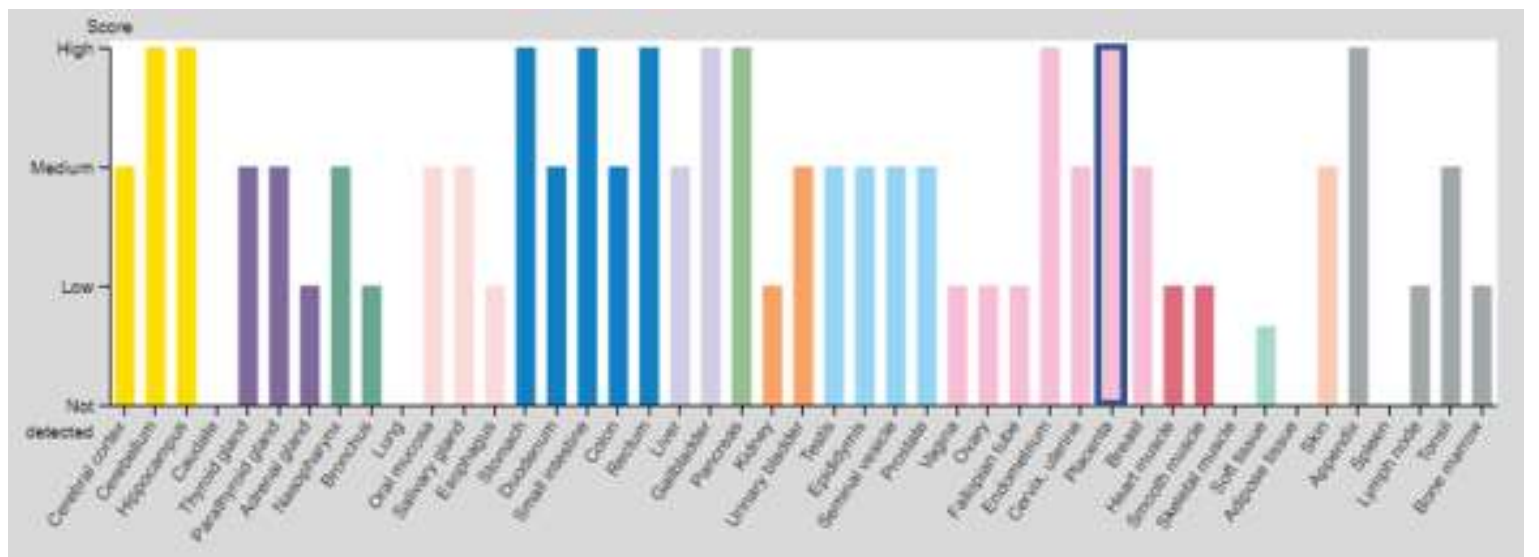


Figure 7: FAR2 Protein Expression in Placenta [Courtesy: Human Protein Atlas(45)]

We next looked into the role of STOM (Stomatin) gene as one of the candidates in our analysis.

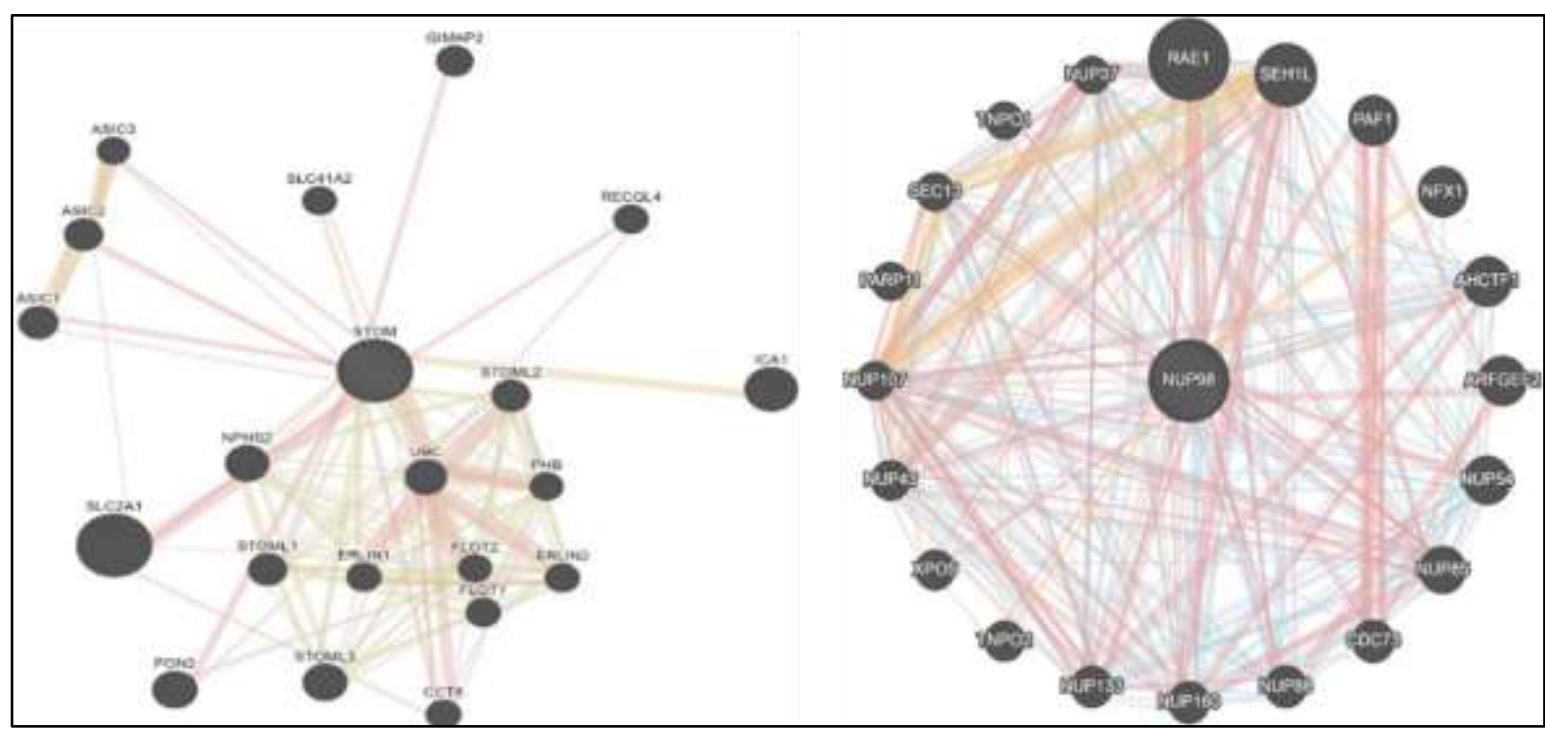

Figure 8: GENEMANIA network showing STOM and NUP98 as hub of a complex interactome. Several cell cycle genes associated with NUP98.

Chen, et al.(46) found that STOM can induce trophoblast fusion and hence could play a role in STB formation. Similarly, NUP98 plays a role in the nuclear pore complex (NPC) assembly and /or maintenance. NUP98, along with NUP96, are involved in bi-directional transport across the NPC. NUP98 seems critical for embryonic stem cell development, as was associated with pregnancy loss.(47) The interaction networks of STOM and NUP98 are shown in Figure 8. Therefore analyzing the genes highly expressed in villous and extravillous trophoblasts, we conclude that several key proteins related to trophoblast fusion, invasion, and genome maintenance seem to be part of SARS-CoV-2 interactome.

\section{SARS-CoV-2 Interacting Proteins that are Upregulated during Villous Trophoblast Differentiation}

Our observation was also reinforced when we analyzed the next data gene set (GSE130339). This gene data set associated with early and latter day 7 trophoblast differentiation (Figure 9). STOM and NUP98 were also found to be enriched here. Of particular interest is FBN2. A recent report published by $\mathrm{Yu} Y$ et al.(48) mentions that FBN encodes asprosin, a glucogenic hormone, following furin cleavage of the C-terminus of profibrillin. They identified a peptide hormone, placensin encoded by FBN2 in trophoblasts of human placenta. Placensin secretion by immortalized human trophoblastic HTR-8/SVneo cells is accompanied by an increase in matrix metalloproteinase-9 (MMP9) expression, thereby promoting cell invasion.

FBN2 also seems to interact with GCM1 (Figure 10), a critical factor for trophoblast differentiation. GCM1 is a master regulator of trophoblast differentiation and seems to be associated with several HDAC complex and is possible that this alters the epigenetic landscape in the cell, an event needed prior to differentiation and lineage commitment. 


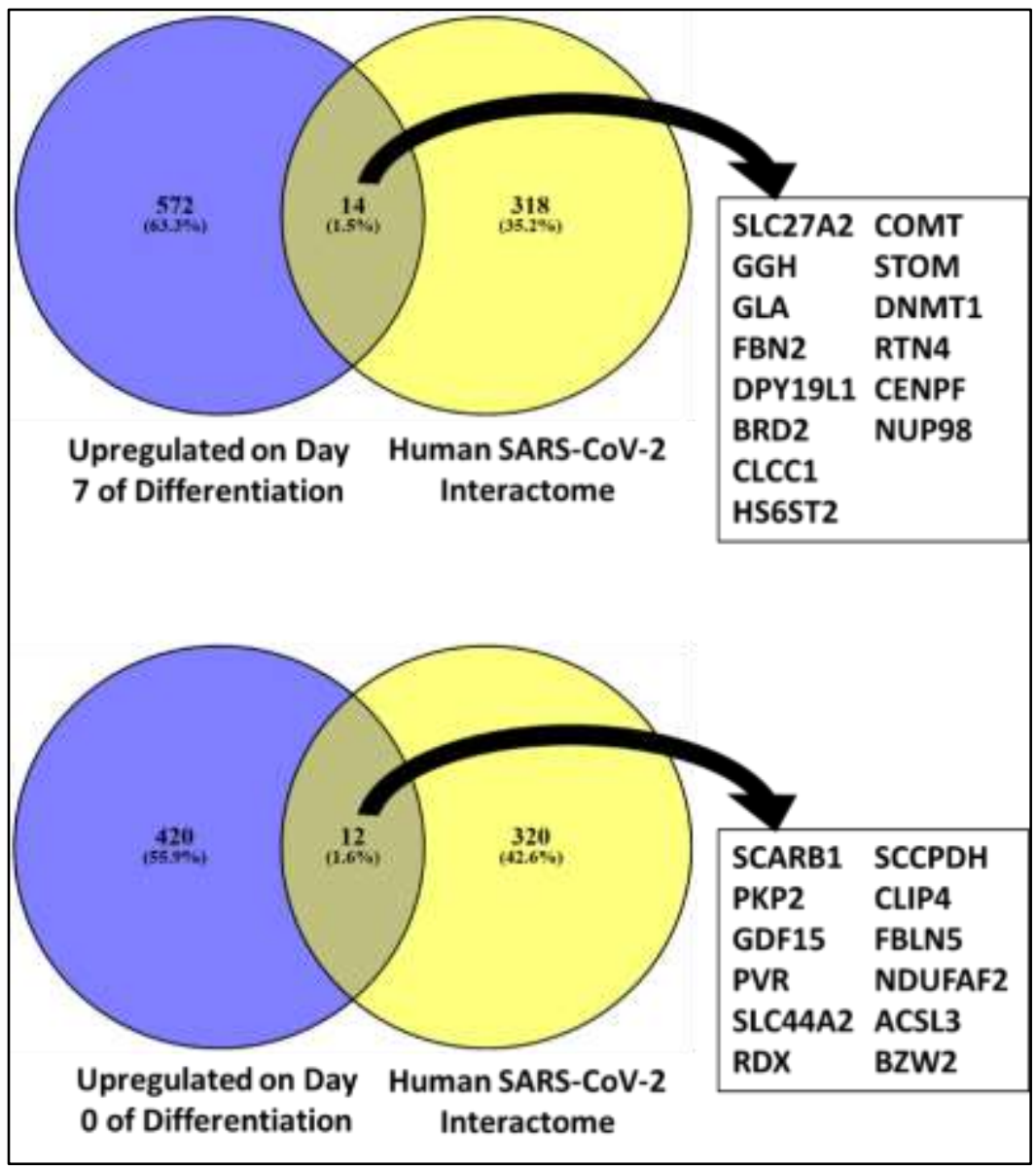

Figure 9: SARS-CoV-2 Interacting Proteins that are Upregulated on Day 0 and Day 7 of Villous Trophoblast Differentiation. The data was obtained by analyzing GSE130339. The expansions of all the gene names are given in Supplementary Table 2.

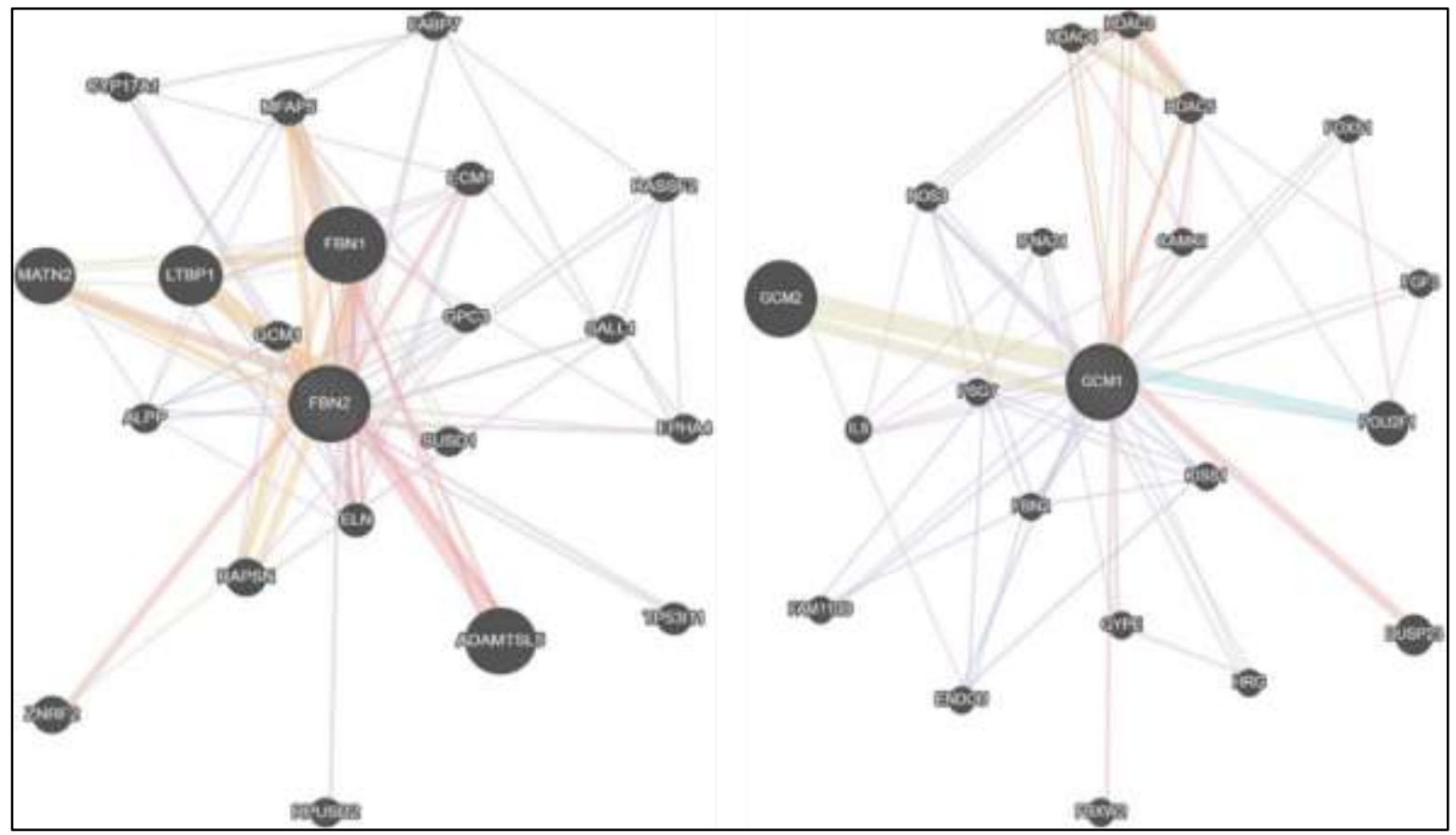

Figure 10: GENEMANIA network showing FBN and GCM1 interactome 
Of interest is GDF15 present in Day 0 differentiation. Recently Turco, et al.(49), using placental organoids derived from early placental villi, found that these cultures organize into villouslike structures and secretes placental-specific peptides and hormones, including human chorionic gonadotropin (hCG), growth differentiation factor 15 (GDF15). This gene encodes a secreted ligand of TGF superfamily, which binds to various TGF-beta receptors leading to recruitment and activation of SMAD family transcription factors that regulate gene expression. GDF15 is involved in trophoblast development where it controls apoptosis and differentiation.(50) GDF15 interactome showed p53 and ERBB2 as close neighbors (Figure 11).

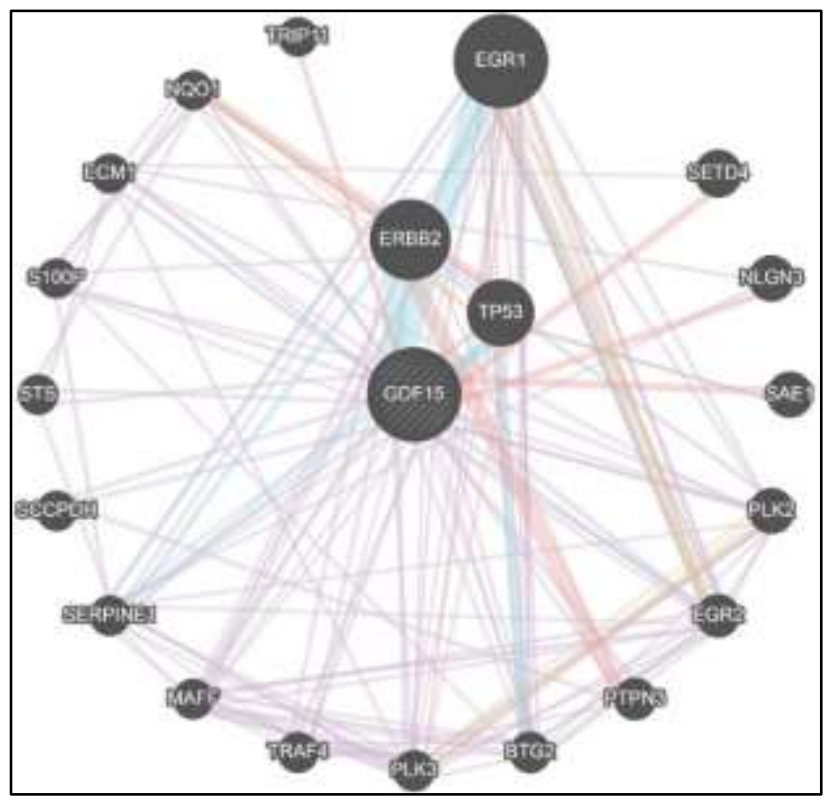

Figure 11: GENEMANIA network showing GDF1 interactome

\section{SARS-CoV-2 Interacting Proteins that are Upregulated in Cytotrophoblasts, Syncytiotrophoblasts and Migrating Trophoblasts}

We did the data mining for SARS-CoV-2 interactome with genes highly expressed in cytotrophoblasts, syncytiotrophoblasts, and migrating trophoblasts (Figure 12). A significant number of genes upregulated in CTB were found to overlap with SARS-CoV-2 interactome (approx. 94, also see supplementary table 3), implying that SARS-CoV-2 can strongly influence CTB stem cells. We observed about ten overlapping proteins related to STB formation.

Of special interest is RBX1, a ring box 1 protein which is found to be abundantly expressed in placenta (Figure 13). Cullin 3 (CUL3), is a scaffold protein that assembles into a large number of ubiquitin ligase complexes, similar to Skp1-Cullin 1-F-box protein complex. CUL3 associates with Bric-a-brac-Tramtrack-Broad (BTB) complex and Rbx1 to form a BTB-CUL3-Rbx1 (BCR) ubiquitin ligase complex. CUL3 was found to be highly expressed in the invasive EVTs of human placenta villi from normal pregnant women, and the expression of CUL3 in the less invasive EVTs from PE patients was significantly lower.(51) CUL3 also promoted the invasion and migration of human trophoblast cells in the human EVT cell line HTR8/SVneo as well as in placental explants. These results show that RbX1 interaction with SARS-CoV-2 proteins is crucial for EVT invasion. 


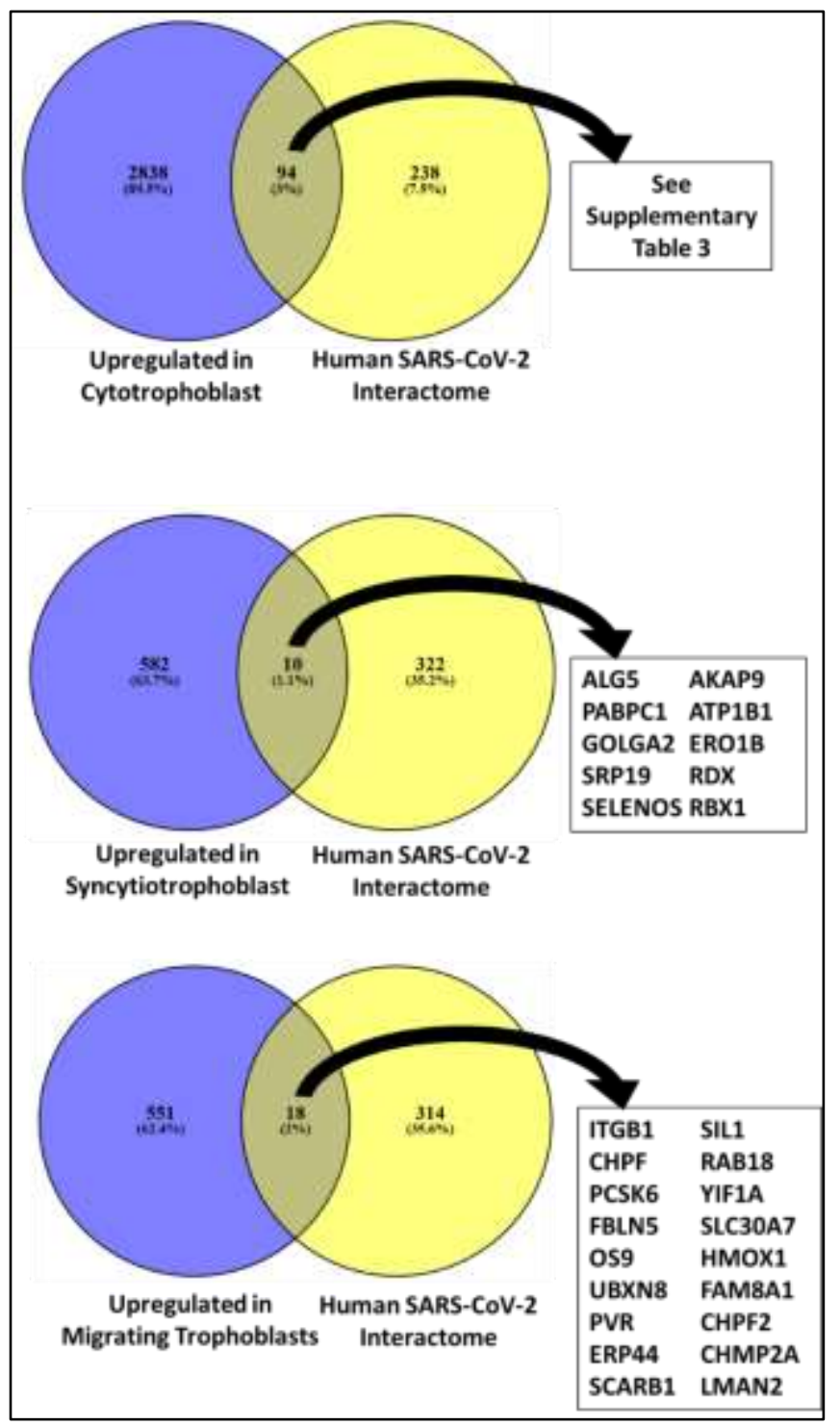

Figure 12: SARS-CoV-2 Interacting Proteins that are Upregulated in Cytotrophoblasts, Syncytiotrophoblasts, and Migrating Trophoblasts. The expansions of all the gene names are given in Supplementary Table 2.

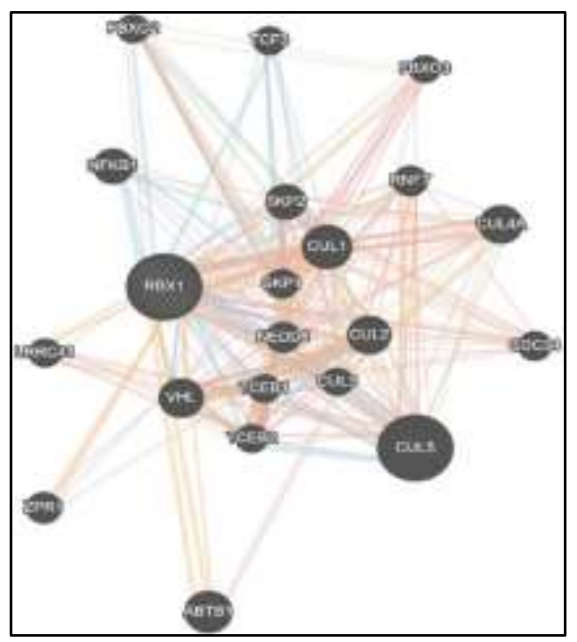

Figure 13: RBX1 CUL3 complex predominantly expressed in invasive EVT 
Further, we found 18 genes related to migratory trophoblast overlapped with SARS-CoV-2 interactome. Of particular interest is HMOX-1, which produces a signaling molecule, carbon monoxide (CO). Bilban, et al.(34) reported that modulation of HMOX-1 expression in loss-offunction as well as gain-of-function cell models (BeWo and HTR8/SVneo, respectively) demonstrated a reciprocal relationship of HMOX-1 expression with trophoblast migration. Also, HMOX-1 expression led to an increase in peroxisome proliferator-activated receptor (PPAR) gamma. The HMOX-1 interactome is depicted in Figure 14.

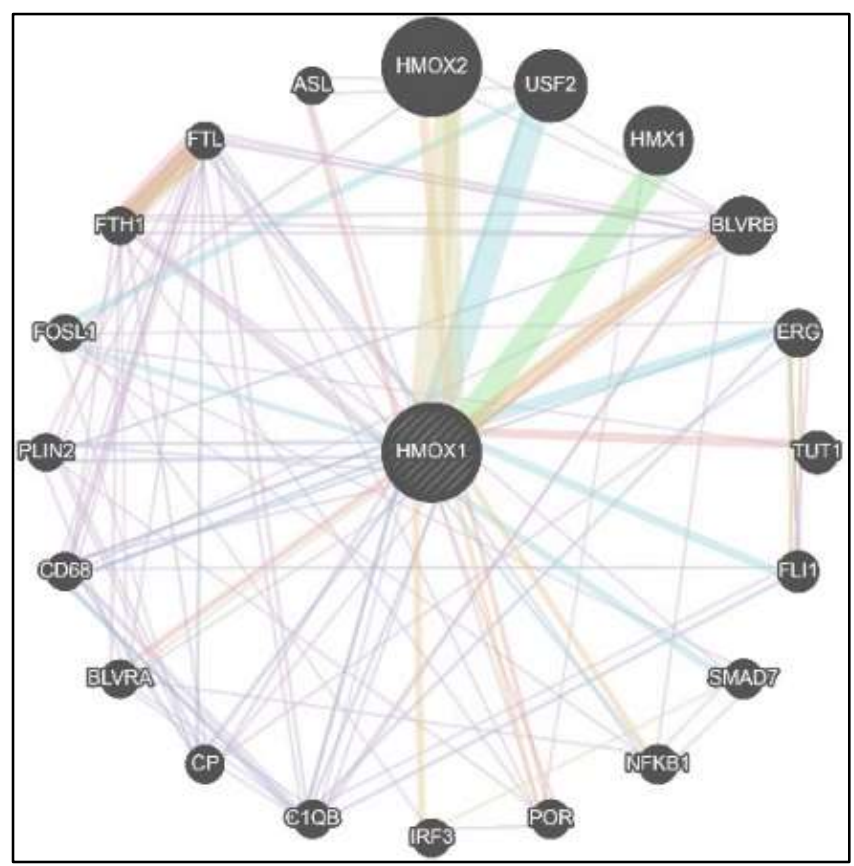

Figure 14: HMOX-1 interactome. Several of the interacting partners play an important role in trophoblast invasion.

\section{SARS-CoV-2 Interacting Proteins that are Upregulated in Placental Cell Lines}

One of the most challenging aspects of placenta research is the availability of fresh tissue samples. Further, with the development of newer and safer methodologies for termination of pregnancy using medications, obtaining first-trimester tissue samples is even more difficult. This has resorted to the placenta researchers using cell lines based approaches to address their biological question. There are currently seven (BeWo, JEG3, SGHPL5, JAR, HTRSVNeo, ACH1P-3P, Spa-26) widely used trophoblasts derived cell lines available, that serve the purpose. These cell lines are more resilient compared to the trophoblast obtained from primary cultures having an extended life span and more comfortable to grow and propagate to address trophoblast function. JEG3, JAR, BeWo, ACH1P-3P are all choriocarcinoma derived, while SGHPL5, HTR, Spa-26, Swan71, TCL-1, RST1, RSVT-2 are all immortalized. Much of our knowledge about the trophoblast system was obtained using these cell lines and immortalized cells as a model system. We next explored that to what extent SARS-CoV-2 interacting proteins overlap with those derived from the cell lines (Figure 15). This will enable us to know if these systems can also be used to study SARS-CoV-2 infection in proxy of using placental trophoblast cells, which are somewhat difficult to obtain in adequate amounts. Our analysis interrogated gene set data from HTR/SVneo, SGHPL5, and JEG3 cell lines, three of the most popular trophoblast cell lines using the dataset GSE20510. 


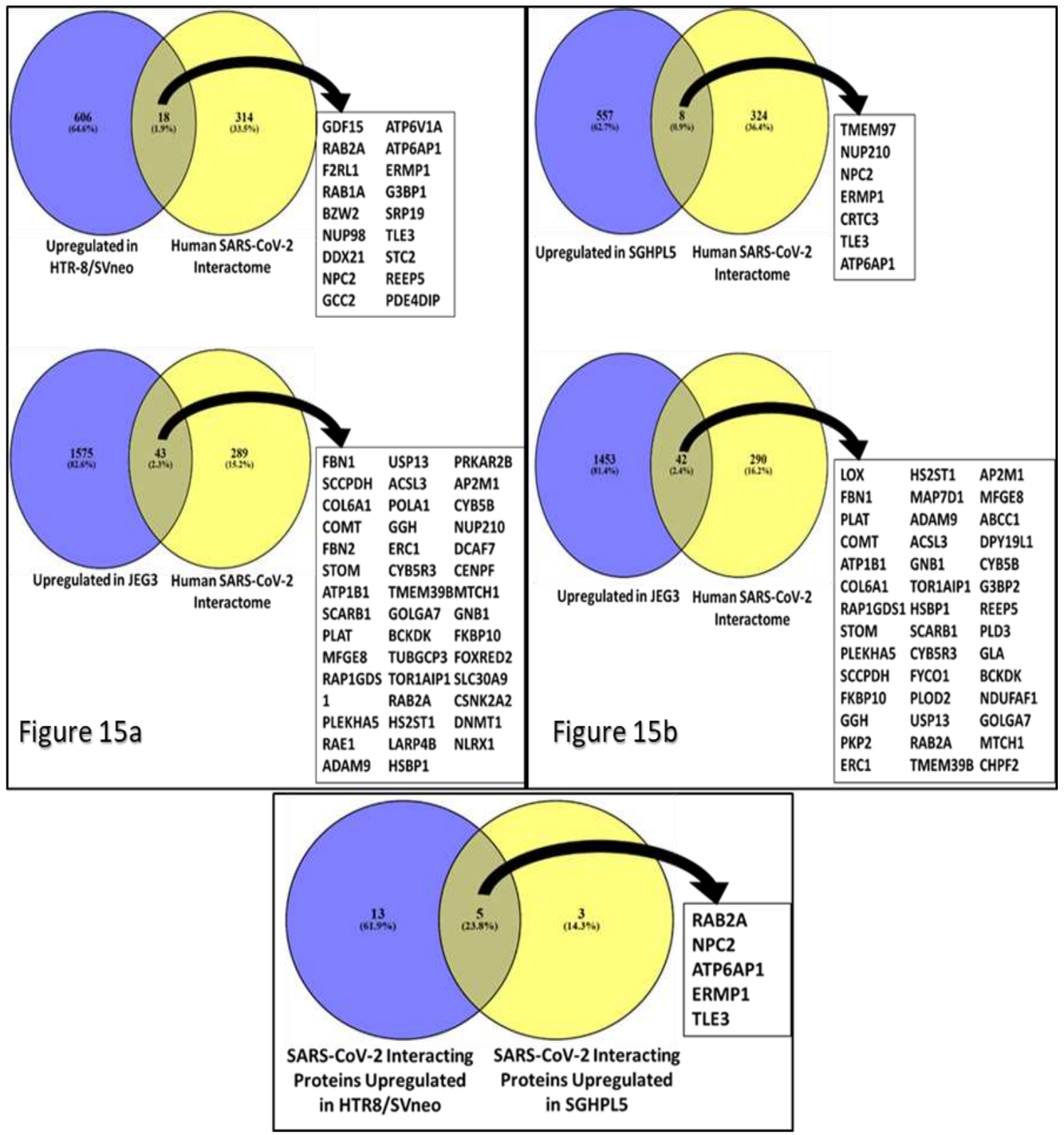

Figure 15c

Figure 15: SARS-CoV-2 Interacting Proteins that are Upregulated in Different Placental Cell Lines. Figure $15 a$ and $15 b$ show genes upregulated in HTR-8/SVneo and SGHPL5 cells, respectively, in comparison with JEG3 cells. Figure 15c shows the overlapping proteins upregulated in HTR-8/SVneo and SGHPL5 that interact with SARS-CoV-2. The dataset used was GSE20510. The expansions of all the gene names are given in Supplementary Table 2.

Our results show 18 and 43 overlapping proteins between HTR/SVneo and JEG3 cell lines, respectively, and 8 and 42 overlapping proteins between SGHPL-5 and JEG3 cell lines, respectively. 5 proteins overlapped between the representative early placental cell lines SGHPL5 and JEG3. We next looked for the overlaps between the genes upregulated in the early placental cell lines - HTR8/SVneo and SGHPL5 - and early placenta and the human SARSCoV2 interactome, using datasets GSE20510 and GSE28551. The result showed the commanility of transducin-like enhancer protein 3 (TLE3) (Figure 16). 


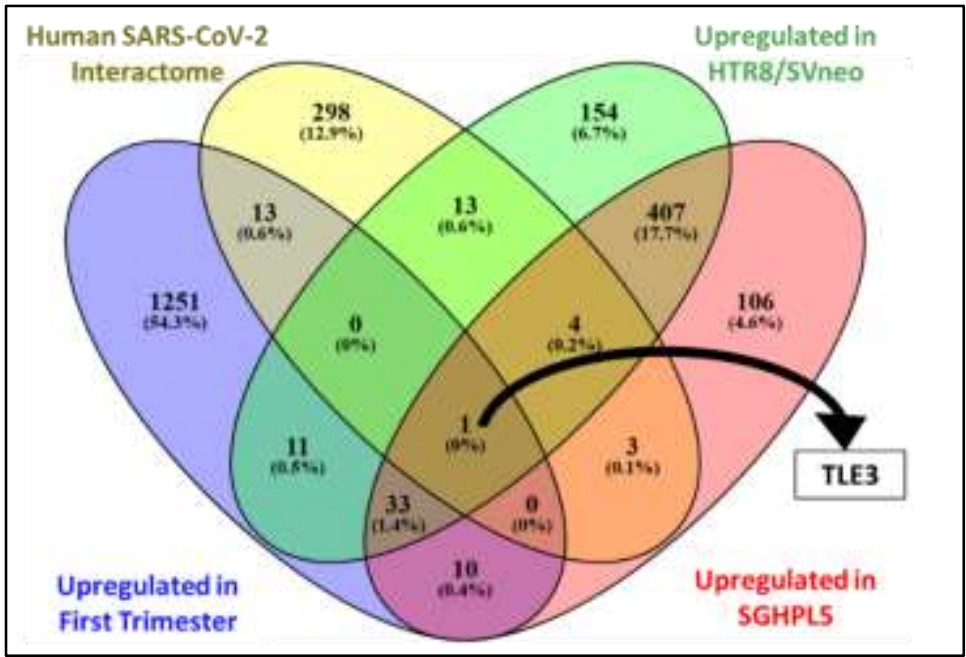

Figure 16: Combined analysis of datasets GSE20510 and GSE28551 involving genes that are upregulated in first trimester placenta and surrogates used in in vitro studies for first-trimester placenta-HTR8/SVneo and SGHPL5 cell lines, and the human SARS-CoV2 interactome.

TLE3 is a transcriptional co-repressor. In murine models, TLE3 known out was associated with abnormal placental development with a severe defect in the vasculature and intrauterine death. TLE3 has also involved in Notch-3 mediated signaling. (52) The interaction network of TLE3 using STRING shows its association with various proteins involved in the transcriptional regulation like Histone deacetylase 1 (HDAC1), CREB-binding protein (CREBBP), C-terminalbinding protein 1 (CTBP1) and Forkhead box protein A1 (FOXA1) (Figure 16a). GENEmania of TLE3 interactome showed strong associations with COPB1 and COPZ1. These are components of coat protein I (COPI) complex which is involved in intracellular protein trafficking. They are also involved in the binding of SARS-CoV (cause of SARS of 2003) spike protein (S protein) to the membrane protein (M-protein) , a process required for viral entry into the endoplasmic reticulum (ER)-Golgi intermediate compartment (ERGIC), budding and viral shedding.(53)

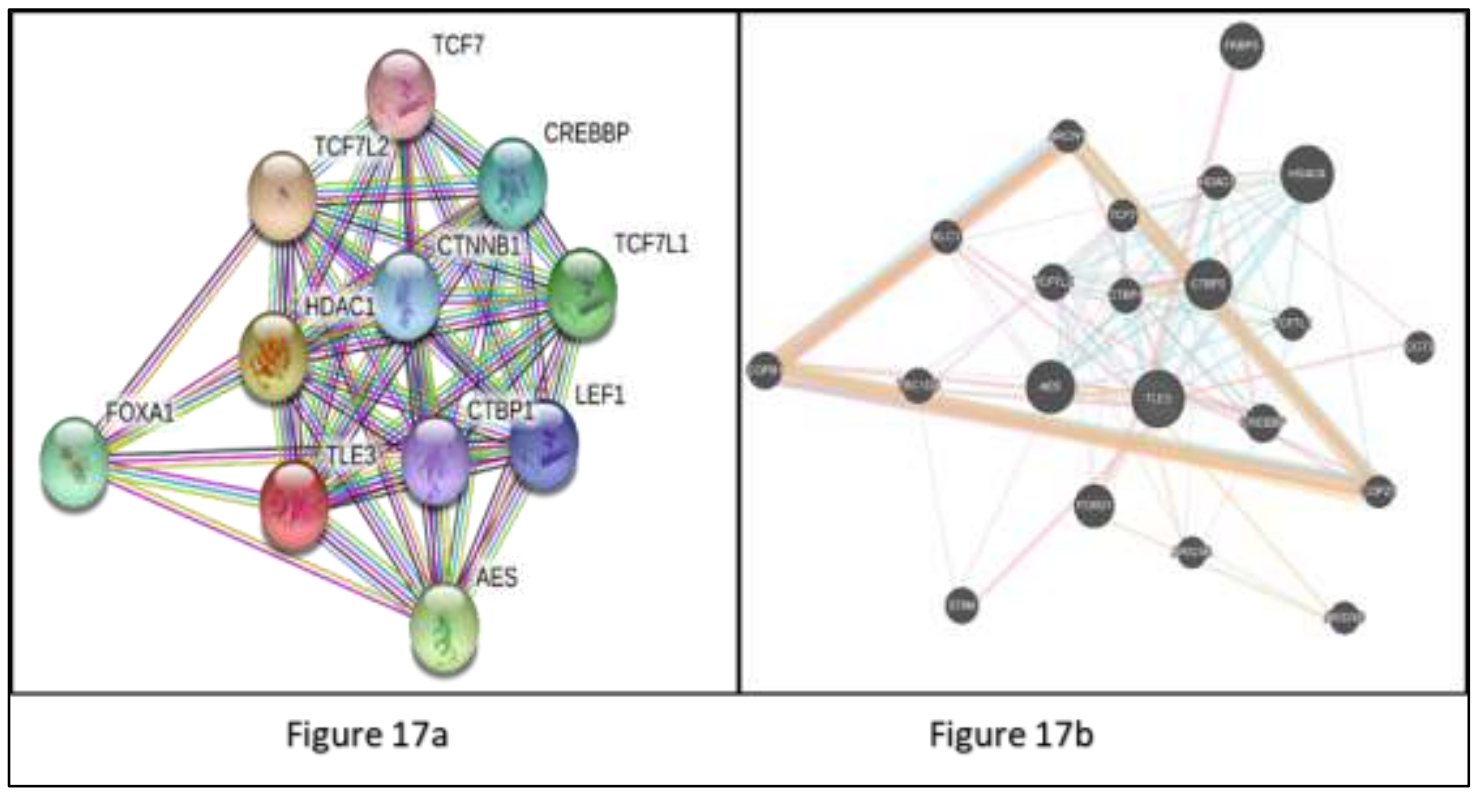

Figure 17: STRING (Figure 17a) and GeneMANIA (Figure 17b) analysis showing TLE3 interacting proteins 
We further explored on ARCNI, as one of the potential TLE3 interacting partners as evident from GeneMANIA (Figures 17b and 18). Results show ARCN1 as a hub, interacting with a large family of COP proteins (COPA, COPB1, COPB2, COPG1, COPG2, COPE, COPZ1) as well as Golgi components (GOLPH3, GOLPH3L). As discussed above, COP plays an important role in virus entry, assembly, and transmission, thereby indicating that these trophoblast cell lines may suffice as a suitable model to study the viral infection cycle.

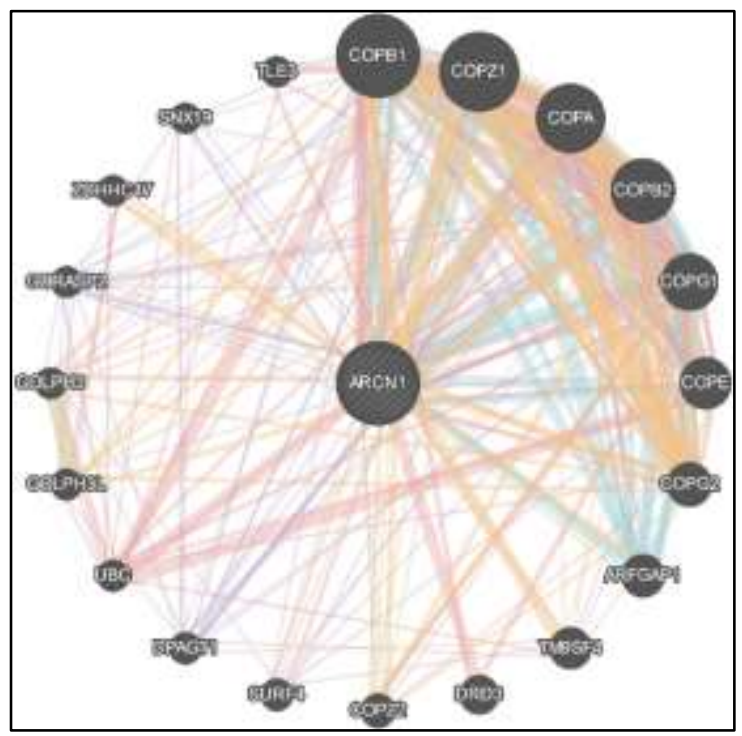

Fig 18. ARCNI interactome showing association with COP complexes

\section{SARS-CoV-2 Interacting Proteins that are Altered in Pre-eclampsia and Gestational Diabetes Mellitus}

So far, we saw that a significant number of genes associated with trophoblast invasion, differentiation, and migration that could potentially interact with SARS-CoV-2. This prompted us to speculate the status of engagement between SARS-CoV-2 and females with preeclampsia (PE) (Figure 5). PE is a common event affecting 10-12\% of pregnant females, usually begins after 20 weeks of pregnancy in a woman whose blood pressure had been normal. It can lead to serious, even fatal complications. ACOG defines gestational hypertension as "hypertension without proteinuria, or severe features develop after 20 weeks of gestation, and blood pressure levels return to normal in the postpartum period". Further, there may be no typical symptoms. High blood pressure and protein in the urine are key features that still might be absent. There may also be swelling in the legs and water retention, but this can be hard to distinguish from a normal pregnancy. Hypertension during pregnancy has been classified into four categories: (i) Preeclampsia/Eclampsia, (ii) Chronic hypertension: This involves hypertension (>140 mm Hg systolic BP or >90 mm Hg diastolic BP) that predates pregnancy, (iii) Chronic hypertension with superimposed preeclampsia and (iv) Gestational hypertension where we have BP elevation in the absence of proteinuria or systemic findings which was formerly known as Pregnancy Induced Hypertension( PIH).

The datasets for PE included GSE66273, where gestational age for PE was 31.0 (30.9-34.0) weeks, and controls were 31.2 (29.3-33.2) weeks, and GSE48424, where gestational age for PE was 34 (31-35) weeks and controls, was (33-37) weeks. Our analysis of the dataset of genes 
overexpressed in preeclampsia using GSE66273 revealed MFGE8 (milk fat globule-epidermal growth factor-factor 8 ) as one of the targets that was also upregulated in PE (Figures 19a and 20).

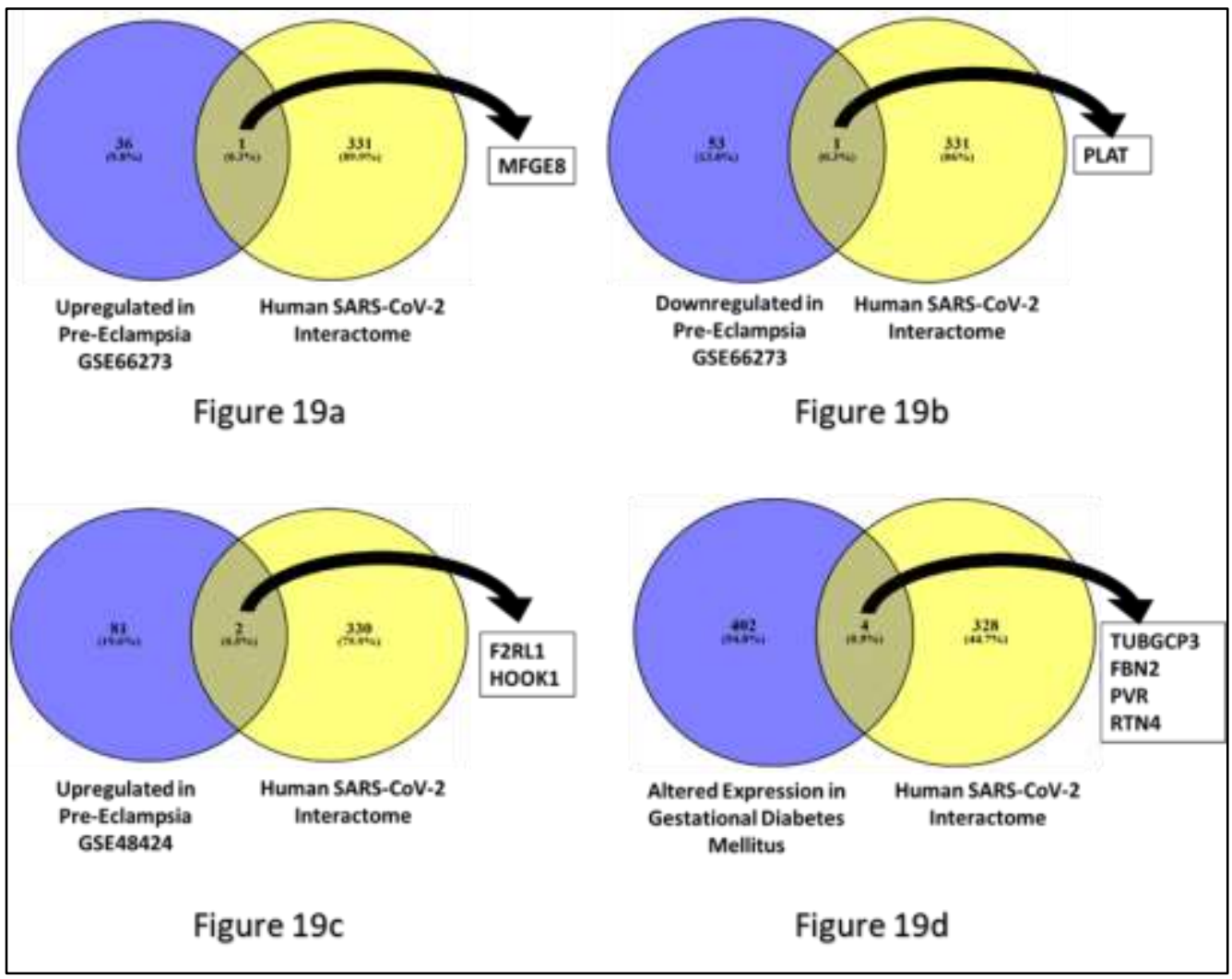

Figure 19: SARS-CoV-2 Interacting Proteins that are Altered in Pre-eclampsia (Figures $19 a, b$, and c) and Gestational Diabetes Mellitus (Figure 19d). The expansions of all the gene names are given in Supplementary Table 2.

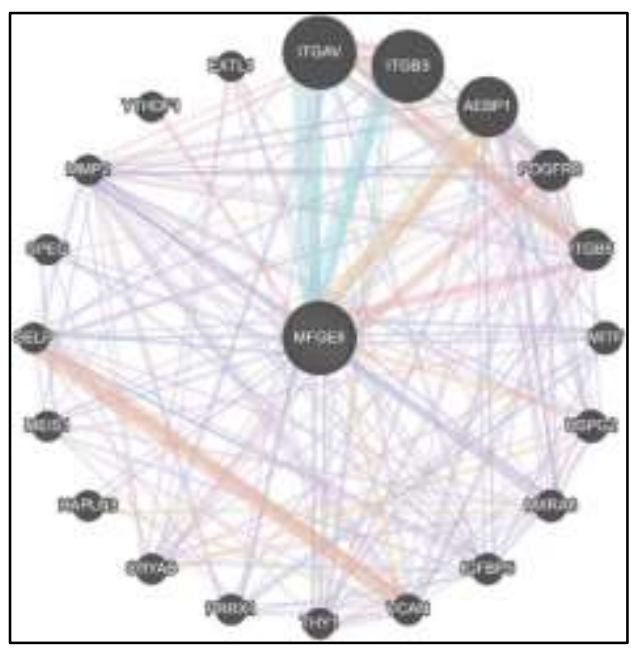

Figure 20: Protein Interaction Network of MFGE8.

MFGE8 protein is highly expressed in human chorionic villi at all trimesters of gestation and in murine implantation sites.(54) MFGE8 performs an important role in physiological conditions during menstrual endometrium remodeling and implantation, and dysfunctions of 
its expression may be associated with endometrial pathological conditions. Further, Schmitz, et al.(55) investigated that MFGE8 and its receptor integrin $\alpha v \beta 3$ play an important role in the attachment of trophoblast cells to the endometrial epithelium. Yu, et al.(56) reported MFGE8 as a master regulator for TGFbeta1 in orchestrating EMT, an event that seems to be dysfunctional in PE. Of particular interest is that MMP2 (72 kDa MMP) as one of the interacting partners for MFGE8 as identified in the gene interaction model (Figure 18). MMP2 has been strongly associated with the onset of PE. $(57,58)$ Therefore; we can conclude that SARS-CoV-2 interaction with MFGE8 could have potentially serious consequences in the onset of PE.

We next investigated the genes down-regulated in PE overlapping with SARS-CoV-2 interactome and identified PLAT as one member (Figure 19b). PLAT (Plasminogen Activator Tissue Type) interaction network comprises (Figure 21) of several serine proteases and their inhibitors - SERPINE1 (also called PAI-1, Plasminogen Activator Inhibitor), PLAU (Plasminogen Urokinase Activator), PLG (Plasminogen). One of the PLAT interacting partners, LRP1 (LDL receptor Related Protein 1) is reported to be poorly expressed in preeclamptic group placental in SGA (Small for Gestational Age) delivering mothers (59) which explains the atherosclerotic phenotype of preeclamptic placentas. Several of the members of this interaction network (SERPINE1, LRP1, PDGFD, JunD) seems to be associated with preeclampsia and $\mathrm{PIH}(60,61)$

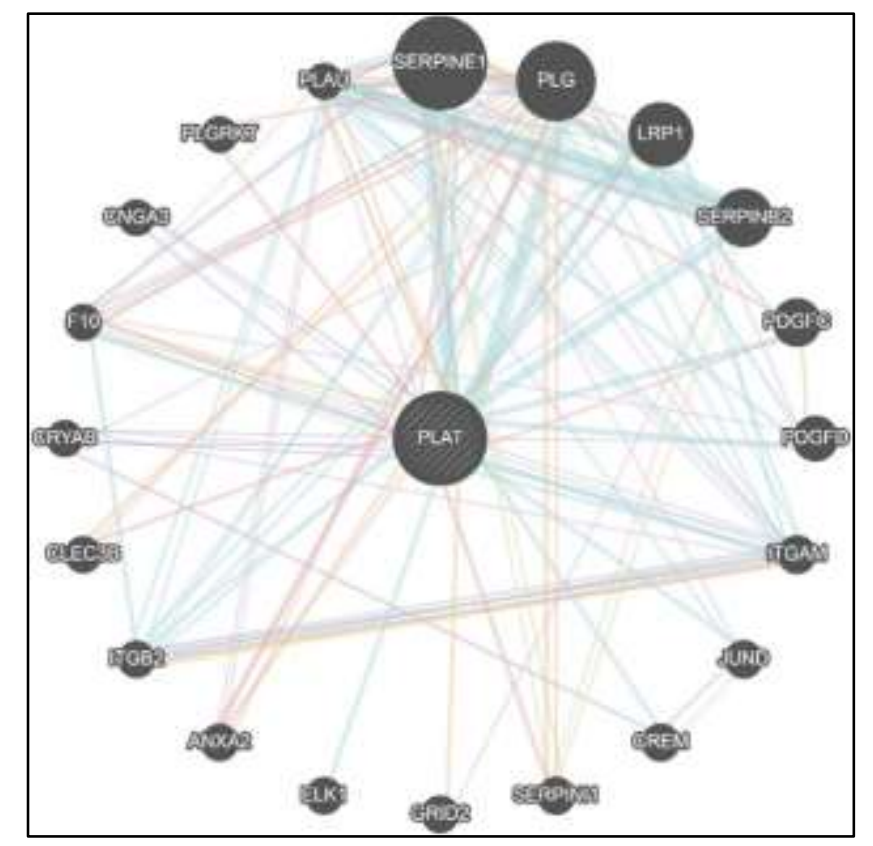

Figure 21: Protein Interaction Network of PLAT

Analysis of GSE48424 (Figure 17c) showed one of the overlapping proteins upregulated in PE and human SARS-CoV-2 as F2LR1. F2LR1 or coagulation factor II (thrombin) receptor-like 1, also known as Protease-activated receptor 2. PAR2 expression was found to be absent in normal placental endothelial cells but overexpressed in placental endothelial cells of preeclampsia patients. Since this is an extracellular receptor, it will be intriguing to know whether pre-eclampsia placental will be at risk for SARS-CoV-2 binding compared to normal pregnancies.(62) 
The list of genes with altered expression in gestational diabetes mellitus (GDM) was obtained from a study by Radaelli, et al.(24) The average gestational age in GDM was $38.5 \pm 0.5$ weeks and in controls was $38.9 \pm 0.4$ weeks. Among the overlapping genes with SARS-CoV-2 (Figure 19d) interactome was FBN2 or Fibulin 2, which has already been mentioned previously as upregulated during extra-villous trophoblast differentiation. Another protein in the common Venn is poliovirus receptor (PVR) or CD155, which was found to interact with actin and integrin alpha- $V$, which are known factors affecting cell motility and migration; thus CD155 is involved in tumor cell invasion and migration, a shared property of tumor cells and trophoblast cells.(63) The STRING analysis also showed the confirmed this finding (Figure 22).

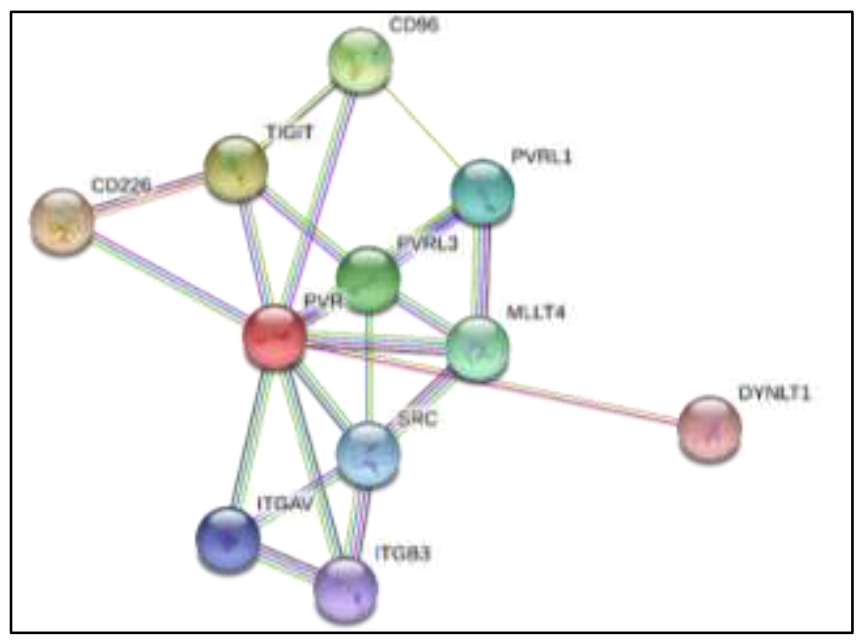

Figure 22: Protein Interaction Network of PVR (CD155)

\section{SARS-CoV-2 Interacting Proteins that are also Involved in Binding to Zika Virus Proteins}

Based on the fact that infection with Zika virus causes fetal abnormality, we explored the overlaps between Zika virus and SARS-CoV-2 interactomes to address if there are any common intersecting pathways and, therefore, could predict the possible outcome of SARSCoV-2 infection on the fetus. Zika virus is transmitted primarily by Aedes aegypti mosquitoes. Though most people with Zika virus infection do not manifest symptoms, during pregnancy, Zika viral infection is reported to cause fetal abnormality in the newborn. Babies were born with microcephaly and other congenital malformations. $(64,65)$ Infection with Zika virus is also associated with other complications of pregnancy, including preterm birth and miscarriage. Zika infection causes microcephaly in the developing fetus is confirmed in the large European cohort study, the EUROCAT (the European Surveillance of Congenital Anomalies) as well in a Brazilian study.(66)

Of the 406 proteins that bind to Zika virus, according to Scaturro et al. (29), 20 were also found to interact with SARS-CoV-2. Among these 20, 10 proteins were highly expressed in cytotrophoblasts, 1 in syncytiotrophoblasts, and 2 in migratory trophoblasts (Figure 23). Thus, 13 human proteins highly expressed in the placenta, which are potentially involved in the pathogenesis of Zika virus infection, are also possible targets of SARS-CoV-2.

Of particular interest are the MRPS (Mitochondrial Ribosomal Proteins)(Figures 24 and 25). These family of proteins plays a crucial role during trophoblast syncytialization process.(67) The human mitochondrial ribosomal protein (MRP) gene family comprises of 30 genes which code for mitochondrial ribosomal small subunit and 50 genes for the large subunit. Poidatz, et al.(67) 
found that MRPS participates in ERR $\gamma$ (Estrogen related receptor-gamma) mediated fusion of trophoblast cell to form a syncytium along with the release of hCG hormone.

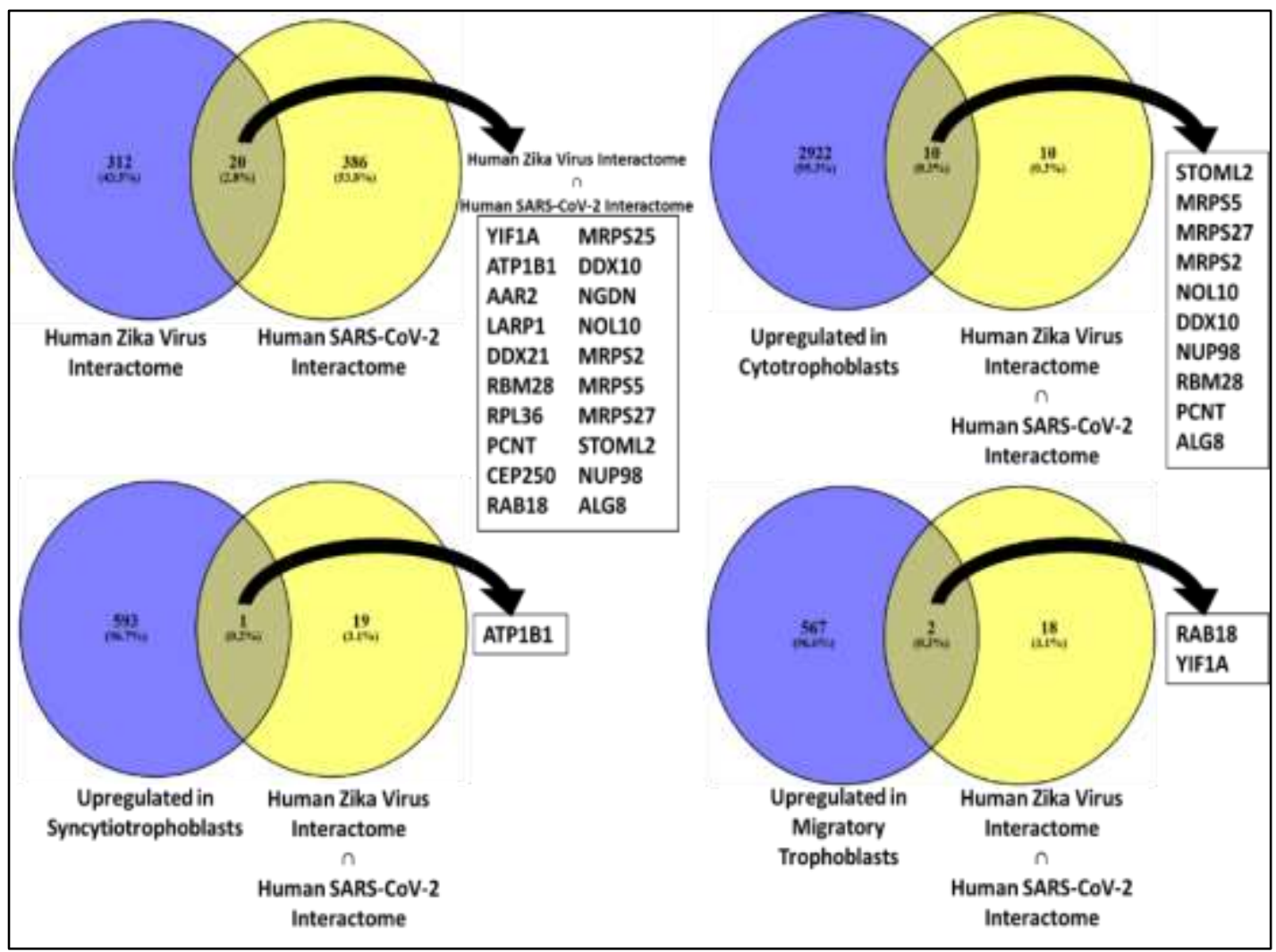

Figure 23: Left Upper Panel Shows the Overlap Between SARS-CoV-2 Interactome and Zika Virus Interactome in Humans. 13 of These Proteins were found to be highly expressed in placenta. The expansions of all the gene names are given in Supplementary Table 2.

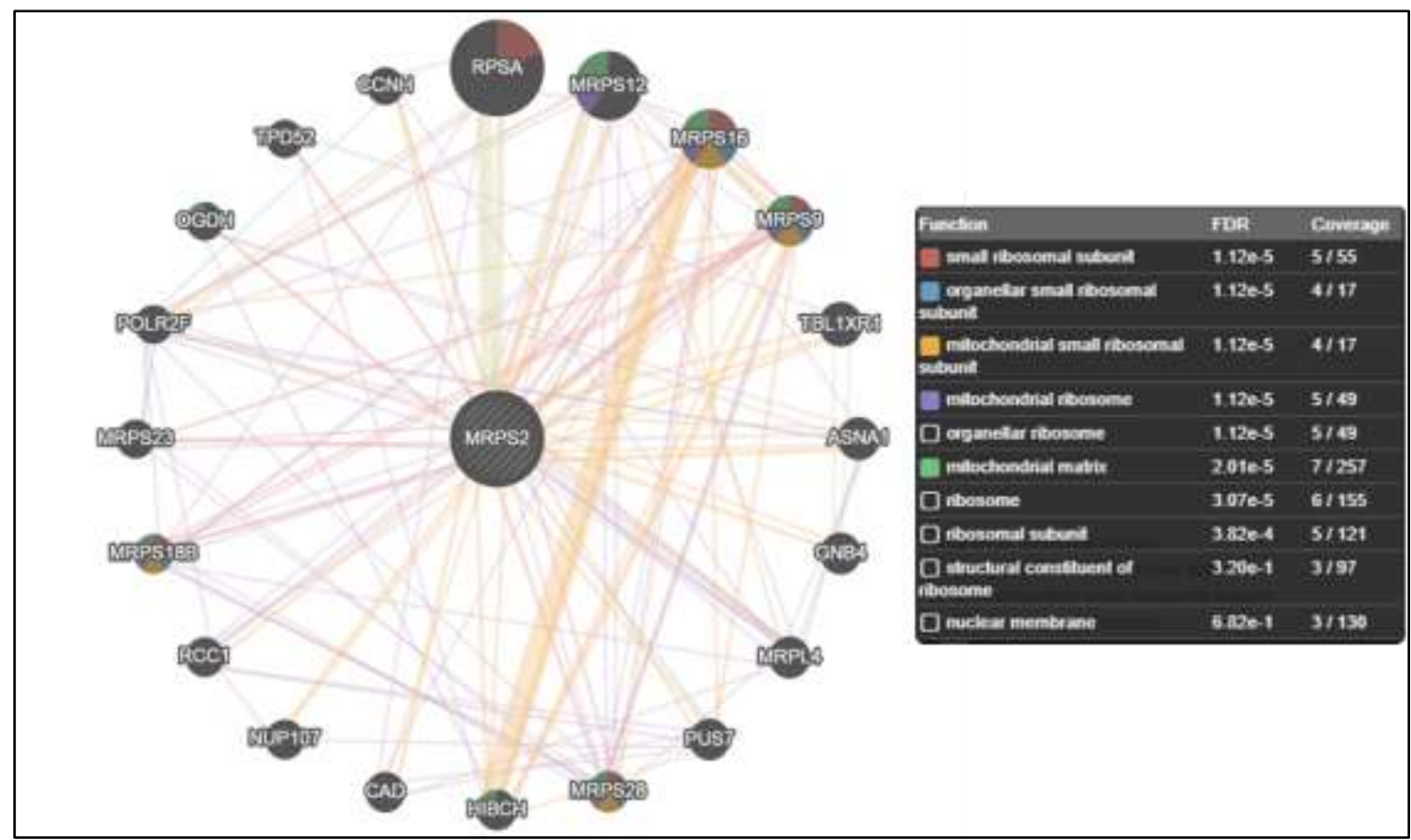

Figure 24: Mitochondrial Ribosomal Protein (MRPS) families showing ALL of their interacting partners 


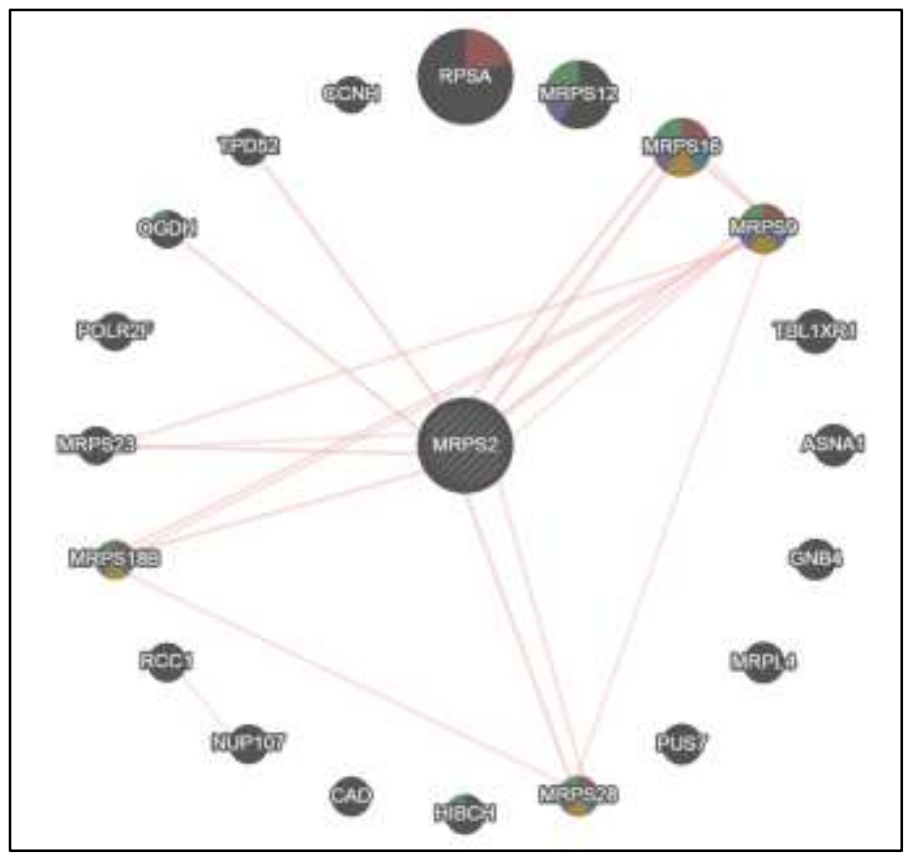

Figure 25: MRSP members physically interacting with each other as a protein complex

Discussion:

We investigated, in silico, the effect of SARS-CoV2 infection in pregnant females. Using a large number of publicly available gene expression data sets from NCBI-GEO related to trophoblast invasion, differentiation, and migration and query against the 332 human interactome as reported by Gordon, et al.(20-22) we identified several overlaps between them. Several of the key genes associated with trophoblast invasion, villous vs. extravillous differentiation, as well as migratory behavior of these cells seem to be a part of this interactome. Our analysis also identified many novel, unreported candidate proteins that could be targeted during these infections. One of the candidate genes that has come up in our analysis is LOX (Lysyl Oxidase), which seems to be differentially expressed between early and term placenta. LOX seems to be interacting with several lysyl oxidases like proteins (LOXL1, L2, L3, L4), collagens ( COL31A), tubulin (TUB), and Apoptotic protease activating factor 1 (APAF1).

In our analysis, we also explored the differentially expressed proteomes from trophoblast cell lines to see their extent of overlaps. The logic of using the cell lines (JEG3, BeWo, SGHPL5, HTR SVneo) is based on the observation that several investigators use these cell lines as a proxy for primary trophoblasts. We found a significant number of overlaps with CoV2, indicating that these cells can be used as a model to study viral infection. Another prominent overlap that was found amongst various early placental tissue and its surrogates and SARSCoV2 interactome was the transcriptional co-repressor TLE3, the functioning of which is vital in the formation of placental vasculature. TLE3 was also found to form networks with components of COPI vesicles, which were found to be vital in the entry of the SARS-CoV-2 to ERGIC, and viral shedding. COPI complexes help to form the vesicle coat that plays a role in traffic contents between Golgi stacks and cargoes between the Golgi apparatus and the endoplasmic reticulum.(68) This also implies that inhibition of COP1 complex using specific pharmacological agents can prevent the virus infection cycle, at least as observed with the influenza virus.(68) 
Since the SARS-CoV-2 interactome reported by Gordon, et al.(20-22) does not include cell surface proteins, we also manually sifted through the list of genes upregulated in various processes and states associated with placenta to check for the entry receptors - ACE2 and TMPRSS2 - of SARS-CoV2.(69) TMPRSS2 is up-regulated in term placenta (GSE28551) while ACE2 is upregulated in extravillous trophoblasts (GSE9773), further making the interaction between SARS-CoV2 and placental tissue probable.

Not only did we analyzed the trophoblast gene expression under normal physiological state and the interaction with the SARS-CoV-2, but we also explored them under pathological states like preclampsia and GDM, two of the most common associated pathological states in pregnancy. We found a few interesting overlapping members, both in PE and GDM. PLAT and MFGE8 in PE is of particular interest as it seems to be associated with serine proteases and their regulators, many of which were reported to be associated with matrix remodeling, invasion, and vasculogenesis. Simialrly, analysis of SARS-CoV-2 and Zika virus interactome showed numerous overlaps, with a number of proteins belonging to the Mitochondrial Ribosomal Protein family, which is important in syncytium formation.

One limitation of the current analysis is that the human proteins interacting with SARS-CoV2 obtained after cloning the viral proteins in HEK293T cells (which are human embryonic kidney cells) may not be exactly similar to the interactome of SARS-CoV-2 in placental cells. However, to the best of our knowledge, there are no reports available on the latter, and at this stage, the former study is unique in that manner. Further, we investigated the abundance of the HEK interacting proteome in placenta and found that a majority of these proteins are also represented in the placental trophoblast cells indicating that we could potentially see these similar interactions conserved there.

We attempted KEGG and GO pathway analysis with DAVID 6.8 (70) for functional annotation of the proteins interacting with SARS-CoV2, that are overlapping with those involved in key roles in placental biology. However, the analysis did not suggest any significant enrichment of specific biological processes or pathways. This could be due to the already restricted number of proteins of the SARS-CoV-2 interactome, which is further narrowed down by a screen for their role in placental function.

There are no clinical reports on the outcome of COVID-19 during the first trimester of pregnancy when the trophoblast invasion and differentiation are very critical. Further, the effect of COVID-19 on pregnancies associated with co-morbidities like preeclampsia and gestational diabetes mellitus is not known. The lack of this information should be factored in before making any rigid conclusions from our study, which is solely based on in silico analysis.

\section{Conclusion:}

Our findings suggest that SARS-CoV-2 might have a profound influence on the placentation process through their effect on the trophoblast cells. Given the fact that several of the viral proteins physically interact with host proteins that are critical components of trophoblast invasion, migration, proliferation, and differentiation processes, we speculate that SARS-CoV2 infection can have detrimental consequences on the pregnancy outcome. We, however, want to add a note of caution that our conclusion is entirely based upon in silico data analysis 
and therefore lack experimental validation. Given the robustness of the process and the individual variability, the final results may differ. It will be interesting to analyze more clinical results to substantiate our prediction. We performed a text mining-based Pubmed search to identify the clinical consequences of COVID-19 on pregnancy. Baergen and Heller (71) observed that amongst 50\% of COVID-19 positive pregnant females, there was evidence of fetal vascular malperfusion or fetal vascular thrombosis, a possibility well predicted in our current study given the fact that SARS-CoV-2 interaction with EVT can alter trophoblast mediated alteration of maternal vasculature, leading to poor perfusion and hypoxia.(72) Stefanovic (73) reported that the rate of Cesarean deliveries among COVID-19 women is unacceptably high and that while significant attention is devoted to the mother, the fetus also needs to be treated as a patient and deserves even more attention. Though clinical studies are limited, following our findings, it becomes, even more, a priority to take into account the possible consequences of COVID-19 on pregnancy outcomes and prepare health care professionals to adopt effective management to avoid an adverse health crisis affecting both mother and the child.

\section{Conflicts of Interest: NONE}

Acknowledgments: We thank BioRender (www.biorender.com) for assistance in making animations (Fig 1\& Fig 5). We also thank the Indian Council of Medical Research (ICMR) for financial assistance to SK and providing fellowship to K Pethusamy. We thank the Council for Scientific and Industrial Research (CSIR) for providing fellowship to IM and SS and the Department of Biotechnology(DBT) for providing salary to RD and KP. We express our sincere gratitude to the All India Institute of Medical Sciences (AIIMS), New Delhi, for providing fellowship to AS.

Authors Contribution: SK and RD oversaw the whole project. SK, RD, and AS performed data analysis and drafted the manuscript with assistance from SS. SS assisted in animations and arranging figures. IM, KP, K Pethusamy also assisted in manuscript preparation, bibliography, and critical discussion. SK and RD want to thank JBS for this assistance with clinical discussion and manuscript preparation. SK expresses his sincere gratitude to the Department of Biochemistry, AlIMS, New Delhi for providing support with infrastructure and logistics.

\section{References:}

1. Zhou P, Yang X-L, Wang X-G, Hu B, Zhang L, Zhang W, et al. A pneumonia outbreak associated with a new coronavirus of probable bat origin. Nature. 2020 Mar;579(7798):270-3.

2. Wu F, Zhao S, Yu B, Chen Y-M, Wang W, Song Z-G, et al. A new coronavirus associated with human respiratory disease in China. Nature. 2020 Mar;579(7798):265-9.

3. Coronavirus Update (Live): 3,146,200 Cases and 218,139 Deaths from COVID-19 Virus Pandemic - Worldometer Available from: https://www.worldometers.info/coronavirus/

4. Report of the WHO-China Joint Mission on Coronavirus Disease 2019 (COVID-19) [Internet]. [cited 2020 Apr 29]. Available from: https://www.who.int/publications-detail/report-of-thewho-china-joint-mission-on-coronavirus-disease-2019-Covid-19) 
5. Sutton D, Fuchs K, D'Alton M, Goffman D. Universal Screening for SARS-CoV-2 in Women Admitted for Delivery. N Engl J Med. 2020 Apr 13;0(0):null.

6. Zhou F, Yu T, Du R, Fan G, Liu Y, Liu Z, et al. Clinical course and risk factors for mortality of adult inpatients with COVID-19 in Wuhan, China: a retrospective cohort study. The Lancet. 2020 Mar 28;395(10229):1054-62.

7. Zhang S, Diao M, Yu W, Pei L, Lin Z, Chen D. Estimation of the reproductive number of novel coronavirus (COVID-19) and the probable outbreak size on the Diamond Princess cruise ship: A data-driven analysis. Int J Infect Dis IJID Off Publ Int Soc Infect Dis. 2020 Feb 22;93:201-4.

8. Rasmussen SA, Smulian JC, Lednicky JA, Wen TS, Jamieson DJ. Coronavirus Disease 2019 (COVID19) and pregnancy: what obstetricians need to know. Am J Obstet Gynecol. 2020 Feb 24;

9. Chen L, Li Q, Zheng D, Jiang H, Wei Y, Zou L, et al. Clinical Characteristics of Pregnant Women with Covid-19 in Wuhan, China. N Engl J Med. 2020 Apr 17;

10. Dashraath P, Wong JLJ, Lim MXK, Lim LM, Li S, Biswas A, et al. Coronavirus disease 2019 (COVID19) pandemic and pregnancy. Am J Obstet Gynecol. 2020 Mar 23;

11. Li Y, Zhao R, Zheng S, Chen X, Wang J, Sheng X, et al. Lack of Vertical Transmission of Severe Acute Respiratory Syndrome Coronavirus 2, China. Emerg Infect Dis. 2020 Jun 17;26(6).

12. Chen H, Guo J, Wang C, Luo F, Yu X, Zhang W, et al. Clinical characteristics and intrauterine vertical transmission potential of COVID-19 infection in nine pregnant women: a retrospective review of medical records. Lancet Lond Engl. 2020 07;395(10226):809-15.

13. Qiao J. What are the risks of COVID-19 infection in pregnant women? Lancet Lond Engl. 2020 07;395(10226):760-2.

14. Dong L, Tian J, He S, Zhu C, Wang J, Liu C, et al. Possible Vertical Transmission of SARS-CoV-2 From an Infected Mother to Her Newborn. JAMA. 2020 Mar 26;

15. Zhu H, Wang L, Fang $\mathrm{C}$, Peng S, Zhang L, Chang G, et al. Clinical analysis of 10 neonates born to mothers with 2019-nCoV pneumonia. Transl Pediatr. 2020 Feb;9(1):51-60.

16. Wong SF, Chow KM, Leung TN, Ng WF, Ng TK, Shek CC, et al. Pregnancy and perinatal outcomes of women with severe acute respiratory syndrome. Am J Obstet Gynecol. 2004 Jul;191(1):292-7.

17. Gude NM, Roberts CT, Kalionis B, King RG. Growth and function of the normal human placenta. Thromb Res. 2004;114(5-6):397-407.

18. Kliman HJ. From Trophoblast to Human Placenta. In: The Encyclopedia of Reproduction Elsevier; 2006. Available from: https://www.elsevier.com/books/encyclopedia-ofreproduction/skinner/978-0-08-091789-4

19. Lee JK, Oh S-J, Park H, Shin OS. Recent Updates on Research Models and Tools to Study VirusHost Interactions at the Placenta. Viruses. 2019 Dec 18;12(1).

20. Malle L. A map of SARS-CoV-2 and host cell interactions. Nat Rev Immunol. 2020 Apr 17; 
21. Gordon DE, Jang GM, Bouhaddou M, Xu J, Obernier K, O'Meara MJ, et al. A SARS-CoV-2-Human Protein-Protein Interaction Map Reveals Drug Targets and Potential Drug-Repurposing. bioRxiv. 2020 Mar 27;2020.03.22.002386.

22. Gordon DE, Jang GM, Bouhaddou M, Xu J, Obernier K, White KM, et al. A SARS-CoV-2 protein interaction map reveals targets for drug repurposing. Nature. 2020 Apr 30;1-13.

23. West RC, Ming H, Logsdon DM, Sun J, Rajput SK, Kile RA, et al. Dynamics of trophoblast differentiation in peri-implantation-stage human embryos. Proc Natl Acad Sci U S A. 2019 05;116(45):22635-44.

24. Radaelli T, Varastehpour A, Catalano P, Hauguel-de Mouzon S. Gestational diabetes induces placental genes for chronic stress and inflammatory pathways. Diabetes. 2003 Dec;52(12):29518.

25. -Venny-. Venn Diagrams for comparing lists. By Juan Carlos Oliveros. 2020 Apr 29. Available from: https://bioinfogp.cnb.csic.es/tools/venny_old/venny.php

26. Warde-Farley D, Donaldson SL, Comes O, Zuberi K, Badrawi R, Chao P, et al. The GeneMANIA prediction server: biological network integration for gene prioritization and predicting gene function. Nucleic Acids Res. 2010 Jul;38(Web Server issue):W214-220.

27. Szklarczyk D, Gable AL, Lyon D, Junge A, Wyder S, Huerta-Cepas J, et al. STRING v11: proteinprotein association networks with increased coverage, supporting functional discovery in genome-wide experimental datasets. Nucleic Acids Res. 2019 08;47(D1):D607-13.

28. Zare Mehrjardi M, Shobeirian F. The role of the placenta in prenatally acquired Zika virus infection. Virusdisease. 2017 Sep;28(3):247-9.

29. Scaturro P, Stukalov A, Haas DA, Cortese M, Draganova K, Płaszczyca A, et al. An orthogonal proteomic survey uncovers novel Zika virus host factors. Nature. 2018 Sep;561(7722):253-7.

30. Xu X-H, Jia Y, Zhou X, Xie D, Huang X, Jia L, et al. Downregulation of lysyl oxidase and lysyl oxidase-like protein 2 suppressed the migration and invasion of trophoblasts by activating the TGF- $\beta /$ collagen pathway in preeclampsia. Exp Mol Med. 2019 Feb;51(2):1-12.

31. Wadsack C, Hammer A, Levak-Frank S, Desoye G, Kozarsky KF, Hirschmugl B, et al. Selective cholesteryl ester uptake from high density lipoprotein by human first trimester and term villous trophoblast cells. Placenta. 2003 Mar;24(2-3):131-43.

32. Kapadia SB, Barth H, Baumert T, McKeating JA, Chisari FV. Initiation of hepatitis C virus infection is dependent on cholesterol and cooperativity between CD81 and scavenger receptor B type I. J Virol. 2007 Jan;81(1):374-83.

33. Pollheimer J, Vondra S, Baltayeva J, Beristain AG, Knöfler M. Regulation of Placental Extravillous Trophoblasts by the Maternal Uterine Environment. Front Immunol. 2018;9:2597.

34. Bilban $M$, Haslinger $P$, Prast J, KlingImüller F, Woelfel T, Haider S. Identification of novel trophoblast invasion-related genes: heme oxygenase-1 controls motility via peroxisome proliferator-activated receptor gamma. Endocrinology. 2009 Feb;150(2):1000-13.

35. Kaufmann P, Castellucci M. Extravillous trophoblast in the human placenta: A review. Placenta. 1997 Jan 1;18:21-65. 
36. Lyall F, Robson SC, Bulmer JN. Spiral artery remodeling and trophoblast invasion in preeclampsia and fetal growth restriction: relationship to clinical outcome. Hypertens Dallas Tex 1979. 2013 Dec;62(6):1046-54.

37. James-Allan LB, Whitley GS, Leslie K, Wallace AE, Cartwright JE. Decidual cell regulation of trophoblast is altered in pregnancies at risk of pre-eclampsia. J Mol Endocrinol. 2018;60(3):23946.

38. Barrientos G, Pussetto M, Rose M, Staff AC, Blois SM, Toblli JE. Defective trophoblast invasion underlies fetal growth restriction and preeclampsia-like symptoms in the stroke-prone spontaneously hypertensive rat. Mol Hum Reprod. 2017 01;23(7):509-19.

39. Chen Z, Wu Q, Yan C, Du J. COL6A1 knockdown suppresses cell proliferation and migration in human aortic vascular smooth muscle cells. Exp Ther Med. 2019 Sep;18(3):1977-84.

40. Owusu-Ansah KG, Song G, Chen R, Edoo MIA, Li J, Chen B, et al. COL6A1 promotes metastasis and predicts poor prognosis in patients with pancreatic cancer. Int J Oncol. 2019 Aug;55(2):391404.

41. Winship A, Cuman C, Rainczuk K, Dimitriadis E. Fibulin-5 is upregulated in decidualized human endometrial stromal cells and promotes primary human extravillous trophoblast outgrowth. Placenta. 2015 Dec;36(12):1405-11.

42. Gauster M, Berghold VM, Moser G, Orendi K, Siwetz M, Huppertz B. Fibulin-5 expression in the human placenta. Histochem Cell Biol. 2011 Feb;135(2):203-13.

43. Moore RM, Redline RW, Kumar D, Mercer BM, Mansour JM, Yohannes E, et al. Differential expression of fibulin family proteins in the para-cervical weak zone and other areas of human fetal membranes. Placenta. 2009 Apr;30(4):335-41.

44. Zhang M, Liu P, Dwyer NK, Christenson LK, Fujimoto T, Martinez F, et al. MLN64 mediates mobilization of lysosomal cholesterol to steroidogenic mitochondria. J Biol Chem. $2002 \mathrm{Sep}$ 6;277(36):33300-10.

45. Uhlén $M$, Björling E, Agaton C, Szigyarto CA-K, Amini B, Andersen E, et al. A human protein atlas for normal and cancer tissues based on antibody proteomics. Mol Cell Proteomics MCP. 2005 Dec;4(12):1920-32.

46. Chen T-W, Liu H-W, Liou Y-J, Lee J-H, Lin C-H. Over-expression of stomatin causes syncytium formation in nonfusogenic JEG-3 choriocarcinoma placental cells. Cell Biol Int. 2016 Aug;40(8):926-33.

47. Kasak L, Rull K, Sõber S, Laan M. Copy number variation profile in the placental and parental genomes of recurrent pregnancy loss families. Sci Rep. 2017 27;7:45327.

48. Yu Y, He J-H, Hu L-L, Jiang L-L, Fang L, Yao G-D, et al. Placensin is a glucogenic hormone secreted by human placenta. EMBO Rep. 2020 Apr 24;e49530.

49. Turco MY, Gardner L, Kay RG, Hamilton RS, Prater M, Hollinshead MS, et al. Trophoblast organoids as a model for maternal-fetal interactions during human placentation. Nature. 2018;564(7735):263-7. 
50. Morrish DW, Dakour J, Li H. Life and death in the placenta: new peptides and genes regulating human syncytiotrophoblast and extravillous cytotrophoblast lineage formation and renewal. Curr Protein Pept Sci. 2001 Sep;2(3):245-59.

51. Zhang $Q$, Yu S, Huang X, Tan Y, Zhu C, Wang Y-L, et al. New insights into the function of Cullin 3 in trophoblast invasion and migration. Reprod Camb Engl. 2015 Aug;150(2):139-49.

52. Gasperowicz M, Surmann-Schmitt C, Hamada Y, Otto F, Cross JC. The transcriptional corepressor TLE3 regulates development of trophoblast giant cells lining maternal blood spaces in the mouse placenta. Dev Biol. 2013 Oct 1;382(1):1-14.

53. McBride CE, Li J, Machamer CE. The Cytoplasmic Tail of the Severe Acute Respiratory Syndrome Coronavirus Spike Protein Contains a Novel Endoplasmic Reticulum Retrieval Signal That Binds COPI and Promotes Interaction with Membrane Protein. J Virol. 2007 Mar 1;81(5):2418-28.

54. Bocca SM, Anderson S, Amaker B, Swanson RJ, Franchi A, Lattanzio F, et al. Milk fat globule epidermal growth factor 8 (MFG-E8): a novel protein in the mammalian endometrium with putative roles in implantation and placentation. Placenta. 2012 Oct;33(10):795-802.

55. Schmitz C, Yu L, Bocca S, Anderson S, Cunha-Filho JS, Rhavi BS, et al. Role for the endometrial epithelial protein MFG-E8 and its receptor integrin $\alpha v \beta 3$ in human implantation: results of an in vitro trophoblast attachment study using established human cell lines. Fertil Steril. 2014 Mar;101(3):874-82.

56. Yu L, Hu R, Sullivan C, Swanson RJ, Oehninger S, Sun Y-P, et al. MFGE8 regulates TGF- $\beta$-induced epithelial mesenchymal transition in endometrial epithelial cells in vitro. Reprod Camb Engl. 2016;152(3):225-33.

57. Espino Y Sosa S, Flores-Pliego A, Espejel-Nuñez A, Medina-Bastidas D, Vadillo-Ortega F, ZagaClavellina V, et al. New Insights into the Role of Matrix Metalloproteinases in Preeclampsia. Int J Mol Sci. 2017 Jul 20;18(7).

58. Chen J, Khalil RA. Matrix Metalloproteinases in Normal Pregnancy and Preeclampsia. Prog Mol Biol Transl Sci. 2017;148:87-165.

59. Hentschke MR, Poli-de-Figueiredo CE, da Costa BEP, Kurlak LO, Williams PJ, Mistry HD. Is the atherosclerotic phenotype of preeclamptic placentas due to altered lipoprotein concentrations and placental lipoprotein receptors? Role of a small-for-gestational-age phenotype. J Lipid Res. 2013 Oct;54(10):2658-64.

60. Sitras V, Paulssen RH, Grønaas H, Leirvik J, Hanssen TA, Vårtun A, et al. Differential placental gene expression in severe preeclampsia. Placenta. 2009 May;30(5):424-33.

61. Briese J, Sudahl S, Schulte HM, Löning T, Bamberger A-M. Expression pattern of the activating protein-1 family of transcription factors in gestational trophoblastic lesions. Int J Gynecol Pathol Off J Int Soc Gynecol Pathol. 2005 Jul;24(3):265-70.

62. Wang Y, Gu Y, Lucas MJ. Expression of thrombin receptors in endothelial cells and neutrophils from normal and preeclamptic pregnancies. J Clin Endocrinol Metab. 2002 Aug;87(8):3728-34.

63. Sloan KE, Eustace BK, Stewart JK, Zehetmeier C, Torella C, Simeone M, et al. CD155/PVR plays a key role in cell motility during tumor cell invasion and migration. BMC Cancer. 2004 Dec;4(1):114. 
64. Szaba FM, Tighe M, Kummer LW, Lanzer KG, Ward JM, Lanthier $P$, et al. Zika virus infection in immunocompetent pregnant mice causes fetal damage and placental pathology in the absence of fetal infection. PLoS Pathog. 2018;14(4):e1006994.

65. Wiwanitkit V. Placenta, Zika Virus Infection and Fetal Brain Abnormality. Am J Reprod Immunol N Y N 1989. 2016;76(2):97-8.

66. Morris JK, Rankin J, Garne E, Loane M, Greenlees R, Addor M-C, et al. Prevalence of microcephaly in Europe: population based study. BMJ. 2016 Sep 13;354:i4721.

67. Poidatz D, Dos Santos E, Gronier H, Vialard F, Maury B, De Mazancourt P, et al. Trophoblast syncytialisation necessitates mitochondrial function through estrogen-related receptor- $\gamma$ activation. Mol Hum Reprod. 2015 Feb;21 (2):206-16.

68. Sun E, He J, Zhuang X. Dissecting the role of COPI complexes in influenza virus infection. J Virol. 2013 Mar;87(5):2673-85.

69. Hoffmann M, Kleine-Weber H, Schroeder S, Krüger N, Herrler T, Erichsen S, et al. SARS-CoV-2 Cell Entry Depends on ACE2 and TMPRSS2 and Is Blocked by a Clinically Proven Protease Inhibitor. Cell. 2020 16;181(2):271-280.e8.

70. Huang DW, Sherman BT, Lempicki RA. Systematic and integrative analysis of large gene lists using DAVID bioinformatics resources. Nat Protoc. 2009;4(1):44-57.

71. Baergen RN, Heller DS. Placental Pathology in Covid-19 Positive Mothers: Preliminary Findings. Pediatr Dev Pathol Off J Soc Pediatr Pathol Paediatr Pathol Soc. 2020 Jun;23(3):177-80.

72. Wintermark P, Boyd T, Parast MM, Van Marter LJ, Warfield SK, Robertson RL, et al. Fetal placental thrombosis and neonatal implications. Am J Perinatol. 2010 Mar;27(3):251-6.

73. Stefanovic V. COVID-19 infection during pregnancy: fetus as a patient deserves more attention. J Perinat Med. 2020 May 13; 


\section{Supplementary Information:}

Supplementary Table 1: Human Proteins Interacting with SARS-CoV-2

\begin{tabular}{|c|c|c|c|c|c|c|}
\hline AP3B1 & DDX21 & TLE3 & TIMM10B & MRPS25 & CLCC1 & SMOC1 \\
\hline BRD4 & RBM28 & TLE5 & TIMM9 & DDX10 & VPS11 & PLEKHF2 \\
\hline BRD2 & RPL36 & GOLGA3 & HDAC2 & LARP7 & SUN2 & FBXL12 \\
\hline CWC27 & GOLGA7 & GOLGA2 & GPX1 & MEPCE & ALG5 & UGGT2 \\
\hline ZC3H18 & ZDHHC5 & GOLGB1 & TRMT1 & NGDN & STOML2 & CHPF2 \\
\hline SLC44A2 & POLA1 & GRIPAP1 & ATP5MG & EXOSC8 & NUP98 & ADAMTS1 \\
\hline PMPCB & PRIM1 & CEP350 & ATP6AP1 & NARS2 & RAE1 & HYOU1 \\
\hline YIF1A & PRIM2 & PDE4DIP & SIGMAR1 & NOL10 & MTCH1 & FKBP7 \\
\hline ATP1B1 & POLA2 & CEP135 & АТР13АЗ & CCDC86 & HEATR3 & ADAM9 \\
\hline ACADM & COLGALT1 & CEP68 & AGPS & SEPSECS & MDN1 & FKBP10 \\
\hline ETFA & PKP2 & CNTRL & CYB5B & EXOSC5 & PLOD2 & SLC9A3R1 \\
\hline STOM & AP2A2 & ERC1 & ACSL3 & EXOSC3 & TOR1A & CHMP2A \\
\hline GGCX & GFER & GCC2 & CYB5R3 & AATF & STC2 & CSDE1 \\
\hline ATP6V1A & ERGIC1 & CLIP4 & RALA & HECTD1 & PLAT & TOMM70 \\
\hline PSMD8 & AP2M1 & NIN & COMT & MRPS2 & ITGB1 & MARK3 \\
\hline REEP5 & GRPEL1 & CEP112 & RAB5C & MRPS5 & CISD3 & MARK2 \\
\hline PMPCA & TBCA & MIPOL1 & RAB7A & EXOSC2 & COL6A1 & DPH5 \\
\hline ANO6 & SBNO1 & USP13 & RAB8A & MRPS27 & PVR & DCTPP1 \\
\hline PITRM1 & BCKDK & GCC1 & RAB2A & GTF2F2 & DNMT1 & MARK1 \\
\hline SLC30A9 & AKAP8 & JAKMIP1 & RAB10 & FBN1 & LOX & РTBP2 \\
\hline FAST & MYCBP2 & CDK5RAP2 & RAB14 & FBN2 & PCSK6 & BAG5 \\
\hline SLC30A7 & SLU7 & AKAP9 & RHOA & NUP214 & INHBE & UBXN8 \\
\hline TUBGCP3 & RIPK1 & GORASP1 & RAB1A & NUP62 & NPC2 & GPAA1 \\
\hline COQ8B & UBAP $2 L$ & FYCO1 & GNB1 & DCAF7 & MFGE8 & WFS1 \\
\hline SAAL1 & TYSND1 & C1orf50 & GNG5 & EIF4H & OS9 & $A B C C 1$ \\
\hline REEP6 & PDZD11 & CEP250 & LMAN2 & NUP54 & NPTX1 & F2RL1 \\
\hline INTS4 & PRRC2B & TBK1 & MOGS & MIB1 & POGLUT2 & SCAP \\
\hline SLC25A21 & UBAP2 & HOOK1 & TOR1AIP1 & SPART & POGLUT3 & DPY19L1 \\
\hline TUBGCP2 & ZNF318 & NINL & MTARC1 & NEK9 & ERO1B & TMEM97 \\
\hline TARS2 & CRTC3 & GLA & QSOX2 & ZNF503 & PLD3 & SLC30A6 \\
\hline RTN4 & USP54 & IMPDH2 & HS2ST1 & NUP88 & FOXRED2 & TAPT1 \\
\hline FAM8A1 & ZC3H7A & SIRT5 & NDUFAF2 & NUP58 & CHPF & ERMP1 \\
\hline AASS & LARP4B & NUTF2 & SCCPDH & MAT2B & PUSL1 & NLRX1 \\
\hline AKAP8L & RBM41 & ARF6 & SCARB1 & FBLN5 & EMC1 & RETREG3 \\
\hline AAR2 & TCF12 & RNF41 & NAT14 & PPT1 & GGH & PIGO \\
\hline BZW2 & PPIL3 & SLC27A2 & DCAKD & CUL2 & ERLEC1 & FAR2 \\
\hline RRP9 & PLEKHA5 & EIF4E2 & FAM162A & MAP7D1 & IL17RA & ECSIT \\
\hline PABPC1 & TВКВР1 & POR & DNAJC19 & THTPA & NGLY1 & ALG8 \\
\hline CSNK2A2 & $\mathrm{CIT}$ & RAP1GDS1 & SELENOS & ZYG11B & HS6ST2 & TMEM39B \\
\hline CSNK2B & HSBP1 & WASHC4 & PTGES2 & TIMM8B & SDF2 & GHITM \\
\hline G3BP1 & PCNT & FKBP15 & RAB18 & RBX1 & NEU1 & ACAD9 \\
\hline PABPC4 & CEP43 & GIGYF2 & MPHOSPH10 & ELOC & GDF15 & NDFIP2 \\
\hline LARP1 & PRKAR2A & IDE & SRP72 & ELOB & TM2D3 & BCS1L \\
\hline FAM98A & PRKACA & TIMM10 & ATE1 & HMOX1 & ERP44 & NDUFAF1 \\
\hline
\end{tabular}




\begin{tabular}{|l|l|l|l|l|l|l|}
\hline SNIP1 & PRKAR2B & ALG11 & NSD2 & TRIM59 & EDEM3 & TMED5 \\
UPF1 & RDX & NUP210 & SRP19 & ARL6IP6 & SIL1 & NDUFB9 \\
MOV10 & CENPF & TIMM29 & SRP54 & VPS39 & POFUT1 & PIGS \\
G3BP2 & TLE1 & DNAJC11 & & & & \\
\hline
\end{tabular}

Supplementary Table 2: Expansion of Abbreviated Protein Names Listed in Various Figures and the SARS-CoV-2 Proteins Interacting with These Proteins

\begin{tabular}{|c|c|c|}
\hline $\begin{array}{l}\text { Protein } \\
\text { Symbol }\end{array}$ & Protein name & $\begin{array}{l}\text { SARS-CoV-2 } \\
\text { Protein }\end{array}$ \\
\hline$A A R 2$ & AAR2 splicing factor homolog(AAR2) & SARS-CoV2 M \\
\hline AATF & Apoptosis antagonizing transcription factor(AATF) & SARS-CoV2 nsp8 \\
\hline$A B C C 1$ & ATP binding cassette subfamily $\mathrm{C}$ member 1 (ABCC1) & SARS-CoV2 orf9c \\
\hline ACAD9 & Acyl-coa dehydrogenase family member 9(ACAD9) & SARS-CoV2 orf9c \\
\hline ACSL3 & Acyl-coa synthetase long-chain family member 3(ACSL3) & SARS-CoV2 nsp7 \\
\hline ADAM9 & ADAM metallopeptidase domain 9(ADAM9) & SARS-CoV2 orf8 \\
\hline AGPS & Alkylglycerone phosphate synthase(AGPS) & SARS-CoV2 nsp7 \\
\hline AKAP8 & A-kinase anchoring protein 8(AKAP8) & SARS-CoV2 nsp12 \\
\hline AKAP\&L & A-kinase anchoring protein 8 like(AKAP8L) & SARS-CoV2 M \\
\hline AKAPG & A-kinase anchoring protein 9(AKAP9) & SARS-CoV2 nsp13 \\
\hline ALG5 & ALG5, dolichyl-phosphate beta-glucosyltransferase(ALG5) & SARS-CoV2 orf3a \\
\hline ALG8 & ALG8, alpha-1,3-glucosyltransferase(ALG8) & SARS-CoV2 orf9c \\
\hline ANO6 & Anoctamin 6(ANO6) & SARS-CoV2 M \\
\hline$A P 2 M 1$ & Adaptor related protein complex 2 mu 1 subunit(AP2M1) & SARS-CoV2 nsp10 \\
\hline ARL6IP6 & $\begin{array}{l}\text { ADP ribosylation factor like gtpase } 6 \text { interacting protein } \\
6(\text { ARL6IP6) }\end{array}$ & SARS-CoV2 orf3a \\
\hline ATP13A3 & Atpase 13A3(ATP13A3) & SARS-CoV2 nsp6 \\
\hline ATP1B1 & Atpase $\mathrm{Na}+/ \mathrm{K}+$ transporting subunit beta $1(\mathrm{ATP} 1 \mathrm{~B} 1)$ & SARS-CoV2 M \\
\hline ATP6AP1 & Atpase $\mathrm{H}+$ transporting accessory protein 1(ATP6AP1) & SARS-CoV2 nsp6 \\
\hline ATP6V1A & Atpase $\mathrm{H}+$ transporting V1 subunit $\mathrm{A}(\mathrm{ATP} 6 \mathrm{~V} 1 \mathrm{~A})$ & SARS-CoV2 M \\
\hline$B C K D K$ & Branched chain ketoacid dehydrogenase kinase(BCKDK) & SARS-CoV2 nsp12 \\
\hline BCS1L & $\begin{array}{l}\text { BCS1 homolog, ubiquinol-cytochrome c reductase } \\
\text { complex chaperone }(\mathrm{BCS} 1 \mathrm{~L})\end{array}$ & SARS-CoV2 orf9c \\
\hline BRD2 & Bromodomain containing 2(BRD2) & SARS-CoV2 E \\
\hline BZW2 & Basic leucine zipper and W2 domains 2(BZW2) & SARS-CoV2 M \\
\hline CCDC86 & Coiled-coil domain containing 86(CCDC86) & SARS-CoV2 nsp8 \\
\hline CENPF & Centromere protein F(CENPF) & SARS-CoV2 nsp13 \\
\hline CEP135 & Centrosomal protein 135(CEP135) & SARS-CoV2 nsp13 \\
\hline CEP250 & Centrosomal protein 250(CEP250) & SARS-CoV2 nsp13 \\
\hline CHMP2A & Charged multivesicular body protein $2 \mathrm{~A}(\mathrm{CHMP} 2 \mathrm{~A})$ & SARS-CoV2 orf9b \\
\hline CHPF & Chondroitin polymerizing factor(CHPF) & SARS-CoV2 orf8 \\
\hline CHPF2 & Chondroitin polymerizing factor 2(CHPF2) & SARS-CoV2 orf8 \\
\hline CLCC1 & Chloride channel CLIC like 1(CLCC1) & SARS-CoV2 orf3a \\
\hline CLIP4 & $\begin{array}{l}\text { CAP-Gly domain containing linker protein family member } \\
4(\text { CLIP4) }\end{array}$ & SARS-CoV2 nsp13 \\
\hline COL6A1 & Collagen type VI alpha 1 chain(COL6A1) & SARS-CoV2 orf8 \\
\hline
\end{tabular}




\begin{tabular}{|c|c|c|}
\hline COMT & Catechol-O-methyltransferase(COMT) & SARS-CoV2 nsp7 \\
\hline CRTC3 & CREB regulated transcription coactivator 3(CRTC3) & SARS-CoV2 nsp12 \\
\hline CSDE1 & Cold shock domain containing E1(CSDE1) & SARS-CoV2 orf9b \\
\hline CSNK2A2 & Casein kinase 2 alpha 2(CSNK2A2) & SARS-CoV2 N \\
\hline CYB5B & Cytochrome b5 type B(CYB5B) & SARS-CoV2 nsp7 \\
\hline CYB5R3 & Cytochrome b5 reductase 3(CYB5R3) & SARS-CoV2 nsp7 \\
\hline DCAF7 & DDB1 and CUL4 associated factor 7(DCAF7) & SARS-CoV2 nsp9 \\
\hline DCAKD & Dephospho-coa kinase domain containing(DCAKD) & SARS-CoV2 nsp7 \\
\hline DCTPP1 & Dctp pyrophosphatase 1(DCTPP1) & SARS-CoV2 orf9b \\
\hline$D D \times 10$ & DEAD-box helicase 10(DDX10) & SARS-CoV2 nsp8 \\
\hline$D D \times 21$ & Dexd-box helicase 21(DDX21) & SARS-CoV2 N \\
\hline DNAJC11 & $\begin{array}{l}\text { Dnaj heat shock protein family (Hsp40) member } \\
\text { C11(DNAJC11) }\end{array}$ & SARS-CoV2 nsp4 \\
\hline DNMT1 & DNA methyltransferase 1(DNMT1) & SARS-CoV2 orf8 \\
\hline DPH5 & Diphthamide biosynthesis 5(DPH5) & SARS-CoV2 orf9b \\
\hline DPY19L1 & Dpy-19 like 1(DPY19L1) & SARS-CoV2 orf9c \\
\hline ECSIT & ECSIT signalling integrator(ECSIT) & SARS-CoV2 orf9c \\
\hline EMC1 & ER membrane protein complex subunit 1(EMC1) & SARS-CoV2 orf8 \\
\hline ERC1 & ELKS/RAB6-interacting/CAST family member 1(ERC1) & SARS-CoV2 nsp13 \\
\hline ERMP1 & Endoplasmic reticulum metallopeptidase 1(ERMP1) & SARS-CoV2 orf9c \\
\hline$E R O 1 B$ & Endoplasmic reticulum oxidoreductase 1 beta(ERO1B) & SARS-CoV2 orf8 \\
\hline ERP44 & Endoplasmic reticulum protein 44(ERP44) & SARS-CoV2 orf8 \\
\hline EXOSC2 & Exosome component 2(EXOSC2) & SARS-CoV2 nsp8 \\
\hline EXOSC3 & Exosome component 3(EXOSC3) & SARS-CoV2 nsp8 \\
\hline EXOSC5 & Exosome component 5(EXOSC5) & SARS-CoV2 nsp8 \\
\hline$F 2 R L 1$ & F2R like trypsin receptor 1(F2RL1) & SARS-CoV2 orf9c \\
\hline FAM8A1 & Family with sequence similarity 8 member A1(FAM8A1) & SARS-CoV2 M \\
\hline FAR2 & Fatty acyl-coa reductase 2(FAR2) & SARS-CoV2 orf9c \\
\hline FASTKD5 & FAST kinase domains 5(FASTKD5) & SARS-CoV2 M \\
\hline FBLN5 & Fibulin 5(FBLN5) & SARS-CoV2 nsp9 \\
\hline FBN1 & Fibrillin 1(FBN1) & SARS-CoV2 nsp9 \\
\hline FBN2 & Fibrillin 2(FBN2) & SARS-CoV2 nsp9 \\
\hline FKBP10 & FK506 binding protein 10(FKBP10) & SARS-CoV2 orf8 \\
\hline FOXRED2 & $\begin{array}{l}\text { FAD dependent oxidoreductase domain containing } \\
\text { 2(FOXRED2) }\end{array}$ & SARS-CoV2 orf8 \\
\hline FYCO1 & FYVE and coiled-coil domain containing 1(FYCO1) & SARS-CoV2 nsp13 \\
\hline G3BP1 & G3BP stress granule assembly factor 1(G3BP1) & SARS-CoV2 N \\
\hline G3BP2 & G3BP stress granule assembly factor 2(G3BP2) & SARS-CoV2 N \\
\hline GCC2 & GRIP and coiled-coil domain containing 2(GCC2) & SARS-CoV2 nsp13 \\
\hline GDF15 & Growth differentiation factor 15(GDF15) & SARS-CoV2 orf8 \\
\hline GGH & Gamma-glutamyl hydrolase(GGH) & SARS-CoV2 orf8 \\
\hline GHITM & $\begin{array}{l}\text { Growth hormone inducible transmembrane } \\
\text { protein(GHITM) }\end{array}$ & SARS-CoV2 orf9c \\
\hline GLA & Galactosidase alpha(GLA) & SARS-CoV2 nsp14 \\
\hline GNB1 & G protein subunit beta $1(\mathrm{GNB} 1)$ & SARS-CoV2 nsp7 \\
\hline GOLGA2 & Golgin A2(GOLGA2) & SARS-CoV2 nsp13 \\
\hline
\end{tabular}




\begin{tabular}{|c|c|c|}
\hline GOLGA7 & Golgin A7(GOLGA7) & SARS-CoV2 Spike \\
\hline GPAA1 & $\begin{array}{l}\text { Glycosylphosphatidylinositol anchor attachment } \\
\text { 1(GPAA1) }\end{array}$ & SARS-CoV2 orf9c \\
\hline GRIPAP1 & GRIP1 associated protein 1(GRIPAP1) & SARS-CoV2 nsp13 \\
\hline HDAC2 & Histone deacetylase 2(HDAC2) & SARS-CoV2 nsp5 \\
\hline HMOX1 & Heme oxygenase 1(HMOX1) & SARS-CoV2 orf3a \\
\hline HOOK1 & Hook microtubule tethering protein 1(HOOK1) & SARS-CoV2 nsp13 \\
\hline HS2ST1 & Heparan sulfate 2-O-sulfotransferase 1(HS2ST1) & SARS-CoV2 nsp7 \\
\hline HS6ST2 & Heparan sulfate 6-O-sulfotransferase 2(HS6ST2) & SARS-CoV2 orf8 \\
\hline HSBP1 & Heat shock factor binding protein 1(HSBP1) & SARS-CoV2 nsp13 \\
\hline$I D E$ & Insulin degrading enzyme(IDE) & SARS-CoV2 nsp4 \\
\hline IMPDH2 & Inosine monophosphate dehydrogenase 2(IMPDH2) & SARS-CoV2 nsp14 \\
\hline INTS4 & Integrator complex subunit 4(INTS4) & SARS-CoV2 M \\
\hline ITGB1 & Integrin subunit beta $1($ ITGB1) & SARS-CoV2 orf8 \\
\hline LARP1 & La ribonucleoprotein domain family member 1 (LARP1) & SARS-CoV2 N \\
\hline LARP4B & La ribonucleoprotein domain family member 4B(LARP4B) & SARS-CoV2 nsp12 \\
\hline LMAN2 & Lectin, mannose binding 2(LMAN2) & SARS-CoV2 nsp7 \\
\hline LOX & Lysyl oxidase(LOX) & SARS-CoV2 orf8 \\
\hline MAP7D1 & MAP7 domain containing 1(MAP7D1) & SARS-CoV2 orf10 \\
\hline MARK1 & Microtubule affinity regulating kinase 1 (MARK1) & SARS-CoV2 orf9b \\
\hline MARK2 & Microtubule affinity regulating kinase 2(MARK2) & SARS-CoV2 orf9b \\
\hline MARK3 & Microtubule affinity regulating kinase 3(MARK3) & SARS-CoV2 orf9b \\
\hline MAT2B & Methionine adenosyltransferase 2B(MAT2B) & SARS-CoV2 nsp9 \\
\hline MDN1 & Midasin AAA atpase 1(MDN1) & SARS-CoV2 orf7a \\
\hline MFGE8 & Milk fat globule-EGF factor 8 protein(MFGE8) & SARS-CoV2 orf8 \\
\hline MOGS & Mannosyl-oligosaccharide glucosidase(MOGS) & SARS-CoV2 nsp7 \\
\hline MOV10 & Mov10 RISC complex RNA helicase(MOV10) & SARS-CoV2 N \\
\hline MRPS2 & Mitochondrial ribosomal protein S2(MRPS2) & SARS-CoV2 nsp8 \\
\hline MRPS25 & Mitochondrial ribosomal protein S25(MRPS25) & SARS-CoV2 nsp8 \\
\hline MRPS27 & Mitochondrial ribosomal protein S27(MRPS27) & SARS-CoV2 nsp8 \\
\hline MRPS5 & Mitochondrial ribosomal protein S5(MRPS5) & SARS-CoV2 nsp8 \\
\hline MTCH1 & Mitochondrial carrier $1(\mathrm{MTCH} 1)$ & SARS-CoV2 orf6 \\
\hline NARS2 & $\begin{array}{l}\text { Asparaginyl-trna synthetase 2, mitochondrial } \\
\text { (putative)(NARS2) }\end{array}$ & SARS-CoV2 nsp8 \\
\hline NDUFAF1 & $\begin{array}{l}\text { NADH:ubiquinone oxidoreductase complex assembly } \\
\text { factor } 1 \text { (NDUFAF1) }\end{array}$ & SARS-CoV2 orf9c \\
\hline NDUFAF2 & $\begin{array}{l}\text { NADH:ubiquinone oxidoreductase complex assembly } \\
\text { factor 2(NDUFAF2) }\end{array}$ & SARS-CoV2 nsp7 \\
\hline NGDN & Neuroguidin(NGDN) & SARS-CoV2 nsp8 \\
\hline NIN & Ninein(NIN) & SARS-CoV2 nsp13 \\
\hline NLRX1 & NLR family member X1(NLRX1) & SARS-CoV2 orf9c \\
\hline NOL10 & Nucleolar protein 10(NOL10) & SARS-CoV2 nsp8 \\
\hline NPC2 & NPC intracellular cholesterol transporter 2(NPC2) & SARS-CoV2 nsp4 \\
\hline NUP210 & Nucleoporin 210(NUP210) & SARS-CoV2 nsp9 \\
\hline NUP54 & Nucleoporin 54(NUP54) & SARS-CoV2 nsp9 \\
\hline NUP58 & Nucleoporin 58(NUP58) & SARS-CoV2 nsp9 \\
\hline
\end{tabular}




\begin{tabular}{|c|c|c|}
\hline NUP62 & Nucleoporin 62(NUP62) & SARS-CoV2 nsp9 \\
\hline NUP88 & Nucleoporin 88(NUP88) & SARS-CoV2 nsp15 \\
\hline NUP98 & Nucleoporin 98(NUP98) & SARS-CoV2 orf8 \\
\hline NUTF2 & Nuclear transport factor 2(NUTF2) & SARS-CoV2 N \\
\hline OS9 & OS9, endoplasmic reticulum lectin(OS9) & SARS-CoV2 N \\
\hline PABPC1 & Poly(A) binding protein cytoplasmic 1(PABPC1) & SARS-CoV2 nsp13 \\
\hline PCNT & Pericentrin(PCNT) & SARS-CoV2 orf8 \\
\hline PCSK6 & Proprotein convertase subtilisin/kexin type 6(PCSK6) & SARS-CoV2 nsp13 \\
\hline PDE4DIP & Phosphodiesterase 4D interacting protein(PDE4DIP) & SARS-CoV2 orf9c \\
\hline PIGO & $\begin{array}{l}\text { Phosphatidylinositol glycan anchor biosynthesis class } \\
\text { O(PIGO) }\end{array}$ & SARS-CoV2 orf9c \\
\hline PIGS & $\begin{array}{l}\text { Phosphatidylinositol glycan anchor biosynthesis class } \\
\text { S(PIGS) }\end{array}$ & SARS-CoV2 M \\
\hline PITRM1 & Pitrilysin metallopeptidase 1(PITRM1) & SARS-CoV2 nsp1 \\
\hline PKP2 & Plakophilin 2(PKP2) & SARS-CoV2 orf8 \\
\hline PLAT & Plasminogen activator, tissue type(PLAT) & SARS-CoV2 orf8 \\
\hline PLD3 & Phospholipase D family member 3(PLD3) & SARS-CoV2 nsp12 \\
\hline PLEKHA5 & Pleckstrin homology domain containing A5(PLEKHA5) & SARS-CoV2 orf8 \\
\hline PLOD2 & $\begin{array}{l}\text { Procollagen-lysine,2-oxoglutarate 5-dioxygenase } \\
\text { 2(PLOD2) }\end{array}$ & SARS-CoV2 M \\
\hline$P M P C A$ & $\begin{array}{l}\text { Peptidase, mitochondrial processing alpha } \\
\text { subunit(PMPCA) }\end{array}$ & SARS-CoV2 M \\
\hline$P M P C B$ & $\begin{array}{l}\text { Peptidase, mitochondrial processing beta } \\
\text { subunit(PMPCB) }\end{array}$ & SARS-CoV2 orf8 \\
\hline POFUT1 & Protein O-fucosyltransferase 1(POFUT1) & SARS-CoV2 nsp1 \\
\hline POLA1 & DNA polymerase alpha 1, catalytic subunit(POLA1) & SARS-CoV2 nsp1 \\
\hline POLA2 & DNA polymerase alpha 2 , accessory subunit(POLA2) & SARS-CoV2 nsp2 \\
\hline POR & Cytochrome p450 oxidoreductase(POR) & SARS-CoV2 nsp1 \\
\hline$P R I M 1$ & Primase (DNA) subunit 1(PRIM1) & SARS-CoV2 nsp1 \\
\hline PRIM2 & Primase (DNA) subunit 2(PRIM2) & SARS-CoV2 nsp13 \\
\hline PRKAR2B & $\begin{array}{l}\text { Protein kinase camp-dependent type II regulatory } \\
\text { subunit beta(PRKAR2B) }\end{array}$ & SARS-CoV2 nsp7 \\
\hline PTGES2 & Prostaglandin E synthase 2(PTGES2) & SARS-CoV2 orf8 \\
\hline PUSL1 & Pseudouridylate synthase-like 1(PUSL1) & SARS-CoV2 orf8 \\
\hline$P V R$ & Poliovirus receptor(PVR) & SARS-CoV2 nsp7 \\
\hline$R A B 10$ & RAB10, member RAS oncogene family(RAB10) & SARS-CoV2 nsp7 \\
\hline$R A B 18$ & RAB18, member RAS oncogene family(RAB18) & SARS-CoV2 nsp7 \\
\hline$R A B 1 A$ & RAB1A, member RAS oncogene family(RAB1A) & SARS-CoV2 nsp7 \\
\hline$R A B 2 A$ & RAB2A, member RAS oncogene family(RAB2A) & SARS-CoV2 nsp7 \\
\hline$R A B 5 C$ & RAB5C, member RAS oncogene family(RAB5C) & SARS-CoV2 nsp7 \\
\hline$R A B 7 A$ & RAB7A, member RAS oncogene family(RAB7A) & SARS-CoV2 nsp7 \\
\hline$R A B 8 A$ & RAB8A, member RAS oncogene family(RAB8A) & SARS-CoV2 orf6 \\
\hline RAE1 & Ribonucleic acid export 1(RAE1) & SARS-CoV2 nsp2 \\
\hline RAP1GDS1 & Rap1 gtpase-GDP dissociation stimulator 1(RAP1GDS1) & SARS-CoV2 N \\
\hline RBM28 & RNA binding motif protein $28(\mathrm{RBM} 28)$ & SARS-CoV2 orf10 \\
\hline$R B X 1$ & Ring-box 1(RBX1) & SARS-CoV2 nsp13 \\
\hline
\end{tabular}




\begin{tabular}{|c|c|c|}
\hline$R D X$ & Radixin(RDX) & SARS-CoV2 M \\
\hline REEP5 & Receptor accessory protein 5(REEP5) & SARS-CoV2 N \\
\hline$R P L 36$ & Ribosomal protein L36(RPL36) & SARS-CoV2 N \\
\hline$R R P 9$ & $\begin{array}{l}\text { Ribosomal RNA processing 9, small subunit (SSU) } \\
\text { processome component, homolog (yeast)(RRP9) }\end{array}$ & SARS-CoV2 M \\
\hline RTN4 & Reticulon 4(RTN4) & SARS-CoV2 M \\
\hline SAAL1 & Serum amyloid $\mathrm{A}$ like 1 (SAAL1) & SARS-CoV2 nsp12 \\
\hline SBNO1 & Strawberry notch homolog 1(SBNO1) & SARS-CoV2 nsp7 \\
\hline SCARB1 & Scavenger receptor class B member 1(SCARB1) & SARS-CoV2 nsp7 \\
\hline SCCPDH & Saccharopine dehydrogenase (putative)(SCCPDH) & SARS-CoV2 nsp7 \\
\hline SELENOS & Selenoprotein S(SELENOS) & SARS-CoV2 nsp6 \\
\hline SIGMAR1 & Sigma non-opioid intracellular receptor 1(SIGMAR1) & SARS-CoV2 orf8 \\
\hline SIL1 & SIL1 nucleotide exchange factor(SIL1) & SARS-CoV2 M \\
\hline SLC25A21 & Solute carrier family 25 member 21 (SLC25A21) & SARS-CoV2 nsp2 \\
\hline SLC27A2 & Solute carrier family 27 member 2(SLC27A2) & SARS-CoV2 M \\
\hline SLC30A7 & Solute carrier family 30 member 7(SLC30A7) & SARS-CoV2 M \\
\hline SLC30A9 & Solute carrier family 30 member 9(SLC30A9) & SARS-CoV2 E \\
\hline SLC44A2 & Solute carrier family 44 member 2(SLC44A2) & SARS-CoV2 orf9b \\
\hline SLC9A3R1 & SLC9A3 regulator 1(SLC9A3R1) & SARS-CoV2 nsp12 \\
\hline SLU7 & SLU7 homolog, splicing factor(SLU7) & SARS-CoV2 nsp8 \\
\hline SRP19 & Signal recognition particle 19(SRP19) & SARS-CoV2 orf8 \\
\hline STC2 & Stanniocalcin 2(STC2) & SARS-CoV2 M \\
\hline STOM & Stomatin(STOM) & SARS-CoV2 orf3b \\
\hline STOML2 & Stomatin like 2(STOML2) & SARS-CoV2 orf3a \\
\hline SUN2 & Sad1 and UNC84 domain containing 2(SUN2) & SARS-CoV2 orf9c \\
\hline TAPT1 & $\begin{array}{l}\text { Transmembrane anterior posterior transformation } \\
\text { 1(TAPT1) }\end{array}$ & SARS-CoV2 M \\
\hline TARS2 & $\begin{array}{l}\text { Threonyl-trna synthetase } 2 \text {, mitochondrial } \\
\text { (putative)(TARS2) }\end{array}$ & SARS-CoV2 nsp13 \\
\hline TLE1 & Transducin like enhancer of split 1(TLE1) & SARS-CoV2 nsp13 \\
\hline TLE3 & Transducin like enhancer of split 3(TLE3) & SARS-CoV2 orf9c \\
\hline TMEMЗ9B & Transmembrane protein 39B(TMEM39B) & SARS-CoV2 orf9c \\
\hline TMEM97 & Transmembrane protein 97(TMEM97) & SARS-CoV2 orf9b \\
\hline TOMM70 & $\begin{array}{l}\text { Translocase of outer mitochondrial membrane } \\
\text { 70(TOMM70) }\end{array}$ & SARS-CoV2 nsp7 \\
\hline TOR1AIP1 & Torsin 1A interacting protein 1(TOR1AIP1) & $\begin{array}{l}\text { SARS-CoV2 } \\
\text { nsp5_C145A }\end{array}$ \\
\hline TRMT1 & Trna methyltransferase 1(TRMT1) & SARS-CoV2 M \\
\hline TUBGCP3 & Tubulin gamma complex associated protein 3(TUBGCP3) & SARS-CoV2 nsp12 \\
\hline UBAP2 & Ubiquitin associated protein 2(UBAP2) & SARS-CoV2 nsp12 \\
\hline UBAP2L & Ubiquitin associated protein 2 like(UBAP2L) & SARS-CoV2 orf9c \\
\hline UBXN8 & UBX domain protein $8($ UBXN8) & SARS-CoV2 orf8 \\
\hline UGGT2 & UDP-glucose glycoprotein glucosyltransferase 2(UGGT2) & SARS-CoV2 nsp13 \\
\hline USP13 & Ubiquitin specific peptidase 13 (isopeptidase T-3)(USP13) & SARS-CoV2 orf9c \\
\hline WFS1 & Wolframin ER transmembrane glycoprotein(WFS1) & SARS-CoV2 M \\
\hline
\end{tabular}




\begin{tabular}{|l|l|l|}
\hline YIF1A & $\begin{array}{l}\text { Yip1 interacting factor homolog A, membrane trafficking } \\
\text { protein(YIF1A) }\end{array}$ & SARS-CoV2 Spike \\
\hline ZDHHC5 & Zinc finger DHHC-type containing 5(ZDHHC5) & SARS-CoV2 nsp12 \\
\hline ZNF318 & Zinc finger protein 318(ZNF318) & SARS-CoV2 M \\
\hline
\end{tabular}

Supplementary Table 3: Proteins Upregulated in Cytotrophoblasts That Interact with SARSCoV-2

\begin{tabular}{|l|l|l|l|l|l|}
\hline FASTKD5 & G3BP1 & CYB5B & NUP88 & POLA2 & HDAC2 \\
\hline STOML2 & TMEM97 & IMPDH2 & ARL6IP6 & AATF & MTCH1 \\
\hline NUP54 & EXOSC3 & GHITM & RRP9 & MAT2B & NUTF2 \\
\hline UBAP2L & EXOSC2 & MRPS5 & NARS2 & PMPCA & DNAJC11 \\
\hline SAAL1 & DCTPP1 & NUP58 & PTGES2 & TUBGCP3 & MRPS27 \\
\hline MRPS2 & RAB10 & TOR1AIP1 & GNB1 & PMPCB & ACAD9 \\
\hline CCDC86 & AGPS & SIGMAR1 & TARS2 & INTS4 & NUP62 \\
\hline EMC1 & NOL10 & CSDE1 & DDX10 & BZW2 & ECSIT \\
\hline SBNO1 & DCAKD & IDE & BRD2 & SLC9A3R1 & SLC30A9 \\
\hline BCKDK & BCS1L & NUP98 & SLC44A2 & POR & GPAA1 \\
\hline CLCC1 & PKP2 & DNMT1 & RBM28 & PIGO & CENPF \\
\hline TRMT1 & UBAP2 & TOMM70 & MOV10 & RAB5C & PRIM1 \\
\hline PCNT & ALG8 & MOGS & ATP6V1A & ZDHHC5 & MARK2 \\
\hline MARK3 & POFUT1 & RAB8A & SUN2 & TLE1 & ANO6 \\
\hline EXOSC5 & AKAP8 & DPH5 & RAE1 & AKAP8L & \\
\hline PIGS & PUSL1 & MDN1 & PITRM1 & ERMP1 & \\
\hline
\end{tabular}

